\title{
El tema de Dios y del hombre en la fenomenología de M. Scheler *
}

\author{
SEGUNDA PARTE \\ EL TEMA DE DIOS EN LA FENOMENOLOGIA DE M. SCHELER
}

\author{
CAPITULO PRIMERO \\ FENOMENOLOGIA DE LA RELIGIÓN \\ VERTIENTE NEGATIVA Y POSITIVA DEL PENSAMIENTO DE M. SCHELER
}

La actitud fenomenológica fundamental de M. Scheler con respecto al tema de Dios en concreto tiene como punto de partida el hecho de que así como «para toda región del ser existen conexiones esenciales (Wesenszusammenhänge), evidentes y materiales (a priori) frente a cualquier experiencia positivo-inductiva y una clase de actos que corresponden legítima y esencialmente a su posible intuición... en el pensamiento religioso existe (también una lógica del ser que, como toda lógica, incluye en sí la lógica formal y la teoría de los objetos y que al mismo tiempo va ya más allá de ésta hasta llegar a las evidencias óntico-esenciales de la esfera del ser y del objeto religioso, a la que por otra parte sería imposible llegar por otra esfera extrarreligiosa»'.

M. Scheler se coloca así, como de golpe, en el mismo núcleo del planteamiento fenomenológico, defendiendo la irreductibilidad e independencia de la "esfera del Absoluto», la esfera religiosa, e impugnando simultáneamente todos aquellos sistemas que intentan reducirla a una esfera distinta, negando asi su plena autonomía.

Hacemos a continuación una breve selección de los sistemas aludidos para resaltar luego la postura scheleriana concreta.

* Cfr. Estudio Agustiniano, 13 (1978) 465-522.

1. Ew. M. 274. 


\section{SISTEMAS CONTRARIOS}

\section{Subjetivismo gnoseológico-religioso}

El subjetivismo gnoseológico se basa en el principio de que «una esfera óntica de objetos puede estar determinada - e incluso "creada» - exclusivamente por actos y operaciones espirituales, a través de los que únicamente es accesible al hombre» ${ }^{2}$.

Es, pues, resultado inmediato de la revolución copernicana realizada por Kant.

Remitimos, por no entrar en el propósito de nuestro estudio, a los autores ya clásicos sobre este punto ${ }^{3}$.

Al preguntarse Kant, a lo Copérnico, si no tendría más éxito en los problemas de la metafísica aceptar que son los objetos los que deben ureglarse") por nuestros conocimientos ${ }^{4}$, opera un giro radical sobre la conciencia trascendental que sólo conoce a priori en las cosas lo que ha puesto precisamente en ellas. El orden del ser no determina ya al conocimiento, sino al contrario, es el orden del conocimiento el que condiciona las esferas del ser.

El subjetivismo gnoseológico trascendental que emerge de Kant, es continuado, de una manera más radical por la escuela neokantiana de Marburgo.

En Kant no se da la autonomía de la razón que en estos neokantianos, por cierto. Aquélla necesita el concurso de la sensibilidad y ésta de la intuición empírica. La escuela neokantiana de Marburgo es más extremada. En ella no tiene ya ningún sentido rel inquirir sobre la existencia de órganos y funciones cognoscitivo-subjetivas, estructuralmente diferentes que estén subordinadas a la diversidad de esferas de posible realidad" ${ }^{5}$. La esfera de lo religioso no tiene una consistencia objetiva en sí, sino solamente lógica-formal proveniente de la «razón», que se proyecta de una manera uniforme sobre todas las esferas del conocer.

Esta uniformidad universal de la razón no permite ningún desarrollo histórico, ni diferencia alguna esencial de los portadores de los distintos valores culturales.

\section{Sübjetivismo psicologista: Schleiermacher}

Hay en esta actitud, para M. Scheler, un coeficiente muy elevado de

2. Ew. M. 150

3. E. Cassirer, El problema del conocimiento, Méjico-Buenos Aires: Fondo de Cultura Económica 1956, Vol. II.

4. Kant, Kritik der reinen Vernunft. Philosophische Bibliotek, Hamburg: F. Meiner 1956, B $X V I-X V I I$ 
mentalidad protestante ${ }^{6}$. El fenómeno religioso punto de convergencia de Dios y hombre, divino y humano, eternidad y tiempo, es interpretado parcialmente; como perteneciente "únicamente» a la esfera del sentimiento.

Esbocemos su génesis histórica: Schleiermacher se encuentra en la encrucijada de dos concepciones que desconocen la esencia de lo religioso: la de la llustración y la de Kant. La primera reduce la Religión a puro «pensamiento», a "conocimiento metafísico de lo Absoluto" ", teniendo por su parte en Kant - según el criterio particial de M. Scheler - una dimensión netamente moral ${ }^{8}$.

Al impugnar Schleiermacher esta subordinación, que llega incluso a una completa disolución, de la Religión en la metafísica o en la ética, la asigna al mismo tiempo una "provincia propia», irreductible, autónoma e independiente: es la "provincia», la esfera del sentimiento: «allí donde ni se sabe, ni se quiere, alli donde se siente por antonomasia, sin fronteras..., basa la Religión su independencia, como vivencia mística, frente a la ciencia (entendimiento) y la moral (voluntad)» ${ }^{9}$.

M. Scheler interpreta a Schleiermacher desde un ángulo psicologista y censura en su concepción los siguientes errores:

a) "La Religión está mezclada... de panteísmo y subjetivismo" ${ }^{10}$.

b) "Se establece un nexo causal y no intencional-cognoscitivo entre el objeto de la Religión y los sentimientos de dependencia absoluta»" ${ }^{11}$.

c) "Se considera el acto religioso de una manera parcial, como sentimiento (Gefühl) ante todo") ${ }^{12}$

d) "Los actos de las facultades afectivas tan importantes para aprehender la dimensión axiológica, en su relación fundamental originaria o intencional (por tanto, no causal), con la vertiente axiológica de lo Divino - con lo Santo - son equiparados a los sentimientos mismos" ${ }^{13}$.

e) «El ignorar... la posibilidad de una unión mediata o inmediata de la voluntad humana con la divina en los actos del conocimiento religioso, es por lo que Schleiermacher -igualmente que Lutero- establece una separación absoluta entre religión y moral» ${ }^{14}$.

6. Ew. M. 278.

7. "Absolutes Wissen in der Form der Vorstellung» (Hegel).

8. «Erkenntins unserer Pflichten als göttlicher Gebote» (Kant) (Ew. M. 139).

9. E. Brunner, Religionsphilosophie evangelischer Theogie, München: Oldenburg 1926, 18.

10. Ew. M. 280.

11. Ibd.

12. Ew. M. 282

13. Ew. M. 283.

14. Ew. M. 284. 
Apuntamos a título de observación que esta crítica de M. Scheler, no está en total armonía con los intérpretes del campo protestante: R. Otto, por ejemplo, que impugna en principio a Schleiermacher, parece luego apoyarse en él ${ }^{15}$. Más categórico es $W$. Schultz ${ }^{16}$ que afirma taxativamente que $M$. Scheler "no ha entendido la teoría de su adversario".

Dejemos la controversia abierta. Sólo intentamos destacar, que frente al subjetivismo gnoseológico y psicologista, invoca $M$. Scheler la existencia de "una región originaria (ursprünglich) y óntica (Dios)»" ${ }^{17}$, igual que la de "órganos y funciones cognoscitivas... que están subordinadas a la diversidad de esferas" ${ }^{18}$.

\section{Deducción de lo Religioso a partir de los valores culturales.}

Con la misma decisión que $\mathrm{M}$. Scheler rechaza el que se diluya lo Religioso en "conocimiento» o en "sentimiento» recusa toda deducción del mismo, por medio de los valores culturales ${ }^{19}$. Aquí alude $M$. Scheler a W. Windelband ${ }^{20}, \mathrm{~J}$. Cohn ${ }^{21}, \mathrm{P}$. Natorp ${ }^{22}$ y también a su maestro R. Eucken ${ }^{23}$.

Windelband reduce la moralidad axiológica de lo santo a la suma total de lo "bueno», "bello», y "verdadero". Lo santo es para él, la conciencia de lo verdadero, bueno y bello, experimentados como realidad trascendental ${ }^{24}$.

P. Natorp coloca, por su parte, la religión udentro de los límites de la humanidad", convirtiéndola exclusivamente en algo integral en el desarrollo del hombre ${ }^{25}$.

En J. Cohn la legitimidad de existencia de la religión se fundamenta en que las regiones axiológicas pertenecientes al mundo de la cultura exigen un complemento que las trascienda. En el mundo de lo religioso descubre, pues, solamente un complemento de los valores y bienes culturales ${ }^{26}$.

Una postura intermedia se observa en R. Eucken: en él, lo religioso y lo cultural ni coinciden ni se excluyen, más bien se complementan en cuanto

15. Das Heilige, 26-28. Aufl., München: Ch. Kaiset 1954, 20.

16. "M. Schelers Kritik an Schleiermacher in lutherischer Sicht», en: Studium Generale. Berlin, 14, (1961) 43.

17. Ew. M. 280.

18. Ew. M. 346.

19. Ew. M. 312.

20. W. Windelband, «Das Heilige», en Präludien, Tübingen: Mohr 1915.

21. Der Sinn der gegenwärtigen Kultur. Ein philosophischer Versuch, Leipzig: F. Meiner 1914.

22. Religion innerhalb der Grenzen der Humanität. Ein Kapitel zur Grundlegung der Sozialpädagogik, Tübingen: Mohr 1908.

23. Der Wahrheitsgehalt der Religion, 4. Aufl., Berlin: De Gruyter 1927.

24. W. Windelband, I.c., 305.

25. P. Natorp, I.c., 104.

26. Ew. M. 312. 
que «tan imposible es una religión sin cultura como una cultura sin religión» ${ }^{27}$.

A estas concepciones se opone en $\mathrm{M}$. Scheler de una manera radical la autonomia, independencia e irreductibilidad de lo Santo, de lo religioso. EI santo, no es èl resultado de elevar hasta el límite de lo posible los valores existentes en el genio artístico, p. e., ni en el «bueno» ni en el «justo» incluso: «un hombre en quien se dieran todos estos valores no despertaría nunca la impresión de santidad" ${ }^{28}$.

El santo, propiamente, no es aquél en quien aparece esencialmente lo humano en el cénit de su desarrollo. En el santo se da más bien y ante todo la "virtus infirmitatis», la conciencia de su pequeñez y miseria de cara a Dios. Precisamente es aquí donde de una manera paradójica se manifiesta en él, como en el milagro, la grandeza de lo Divino, siendo el santo en su esencia un «signum Dei», un «kerygma» de Dios.

Es, pues, de todo punto imposible deducir lo Religioso de algo perteneciente a una esfera extrarreligiosa. Esta posición fundamental de M. Scheler, se explica en último término, como veremos, porque «todo saber acerca (über) de Dios se da únicamente a través de (durch) Dios mismo»" ${ }^{29}$.

\section{La teoría de la "proyección» de Feuerbach}

El punto anterior nos obliga a dar un paso atrás en el tiempo. Con esto queremos resaltar la concepción fundamental de $\mathrm{M}$. Scheler, frente al pensamiento de Feuerbach.

Una interprétación - en este punto- de Feuerbach no puede prescindir del contenido teológico del pensamiento de Hegel. Observamos, sin embargo, que aunque el punto de partida de Feuerbach sea Hegel, su horizonte es totalmente distinto.

En Hegel, aparece una «volatilización» del ser del hombre en virtud de la «fenomenología del espíritu absoluto». También Feuerbach se aferra a la negación del dualismo finito-infinito. Sin embargo en el pensamiento de Feuerbach se da un fuerte virage contrapuesto fundamentalmente a la postura de Hegel. En éste todo lo finito es un momento transeúnte del espíritu absoluto. Para Feuerbach, lo central es lo antropológico. El hombre es el sentido último, la última explicación de todo, incluso de lo trascendente. Tiene Feuerbach, como "contexto» a Hegel: invierte, sencillamente, su pensamiento. En la dialéctica cie Hegel, el «no-ser» de lo finito es el «ser» de lo absoluto y el «ser» de éste, el "no-ser» de aquél. Feuerbach, interpreta subjetivamente esta afirmación y se encuentra con su pensamiento central: "La conciencia de Dios, es la propia conciencia del hombre; el conocimiento de Dios es el conocimien-

27. R. Euchen, I.c., 42.

28. EW. M. 312.

29. Ew. M. 245. 
to propio del hombre ${ }^{30}$. La conciencia que tiene el hombre de Dios, es solamente el saberse el hombre a sí mismo, es pura proyección del hombre: «la conciencia de lo infinito no es otra cosa que la conciencia de la infinitud de la misma conciencia»" ${ }^{31}$.

Feuerbach coloca, lo «divino-trascendente» en un sistema de finitud, no rebasando la religión, por esta causa, la esfera de lo subjetivo: «el sentimiento es lo más noble... lo divino en el hombre. ¿Cómo se podría percibir lo divino por el sentimiento no siendo éste de naturaleza divina?» ${ }^{32}$.

Si en el punto precedente se podía hablar de una reducción lógico-formal de la esfera de lo Religioso a los "valores culturales», basada en la posibilidad de ser deducida de éstos, nos encontramos en Feuerbach -igual que veremos inmediatamente en $\mathrm{G}$. Simmel - con una reducción ontológica de lo Religioso a la esfera antropológica o vital, respectivamente.

\section{La teoría de la "objetivación» de G. Simmel}

Es controvertible el hecho de que G. Simmel haya «evadido las rocas del antropologismo de Feuerbach", como estima H. Müller ${ }^{33}$, o si se da simplemente en él unas trasposición del antropologismo de Feuerbach a la esfera de lo vital-universal.

Prescindimos de este problema hermenéutico. Nos basta constatar en G. Simmel, la realidad originaria y fundamental de la «vida» misma que lo inunda todo y que encierra en sí todas aquellas formas que mediante una funcionalización cristalizan en "objetivación» estructural de «mundos», "formas del mundo" o "totalidades del mundo» (Weltganzheiten). Todas estas formas tienen un «substratum» común: lo vital-universal ${ }^{34}$.

Lo religioso no es un caso especial. También está comprendido en lo vital y únicamente es su mera trasposición, es hipostatización, «objetivación» de lo vital ${ }^{35}$.

La religión es como un conjunto de armonías y disonancias de la vida, traspuestas sobre un pensamiento con clave religiosa.

La postura de M. Scheler, es diametralmente opuesta a las concepciones de Feuerbach y de Simmel.

La uesfera del Absoluto» no implica en modo alguno la negación de la existencia humana. Más bien se realiza la verdadera y auténtica antropogénesis por la irrupción de Dios en el hombre mismo. El hombre se hace compren-

30. Das Wesen des Christentums, Hrsgb. von. Schuffenhauer, Berlin: Reuther-Reichard 1956,39 .

31. I.c., 26

32. I.c., 35. 146.

33. Lebensphilosophie und Religion bei G. Simmel, München: Duncker-Humblot 1960,

34. Lebensanschauung, Munchen: Duncker-Humblot 1922, 36.

35. Ew. M. 240. 
sible y fenomenológicamente aprehensible «bajo la luz» de la idea de Dios ${ }^{36}$. El hombre es para M. Scheler un "estadio intermedio» (Zwischen), una "frontera», un «aparecer Dios» en la corriente de la historia ${ }^{37}$, ya que el alma espiritual «representa en su misma esencia la idea eterna de Dios» ${ }^{38}$.

Si Feuerbach considera al hombre en su finitud, $M$. Scheler lo hace en su trascendencia. La persona es para él «portadora de valores» ${ }^{39}$, y en la cumbre de la escala de valores, se encuentra "Lo Santo" ${ }^{40}$.

En contraposición a Feuerbach, parece pasar por alto M. Scheler, ya desde ahora - cegado de grandezas - , la finitud absoluta del hombre: éste es para él «la intención y el gesto de la Trascendencia» ${ }^{41}$.

Lo Divino en M. Scheler no es mera proyección del no-ser del hombre - objetivación de su vertiente de posibilidad-como en Feuerbach; al contrario, el hombre es proyección esencial de Dios ${ }^{42}$.

Igualmente rechaza $M$. Scheler la concepción de G. Simmel: «Intentos como los realizados por $\mathrm{G}$. Simmel de considerar la determinación religiosa de la vida, como la aprehensión entusiástica de algunos contenidos (Dios...,) de modo que la idea de Dios fuera, solamente, una de las llamadas objetivaciones posibles, carecen totalmente de sentido" ${ }^{43}$.

Dentro de la filosofía de la vida, distingue M. Scheler dos actitudes fundamentales, rechazando ambas como contradictorias en sí mismas:

a) la que coloca todo - «fuera de Dios»- dentro de la corriente vital, interpretándolo como mera objetivación de la misma;

b) la que - en sentido bergsoniano - identifica a «Dios» con la misma "vida creadora»" 44 .

Por una parte, la vida está siempre en "camino», en "movimiento-haciaalgo», siendo, pues, imposible el que se fundamente en sí misma, ya que entonces «descansaría» en ella misma. Por otra parte, es en sí mismo contradictorio el tender a Dios, como Dios mismo, y, simultáneamente, como rodeo hacia algo distinto.

Basta una mirada retrospectiva, para certificar que tanto la reducción lógica-formal, como la ontológica de la esfera de lo religioso, desconocen la consistencia objetiva de ésta, igual que su carácter originario y autónomo. $M$. Scheler parte precisamente de estos dos factores, para preguntarse:

¿Puede tener la Religión una base más firme que ella misma? ${ }^{45}$, asegu-

\footnotetext{
36. Eth. 292.

37. U.d.W. 186.

38. Sym. 137.

39. Eth. 95.

40. Eth. 125.

41. U.d.W. 186.

42. U.d.W. 27.

43. Ew. M. 240-241.

44. Ew. M. 240.

45. Ew. M. 274.
} 
rando a su vez que "los criterios de verdad y de todos los demás valores del conocimiento religioso solamente pueden encontrarse en la misma esencia de la Religión» ${ }^{46}$.

\section{SISTEMAS IMPUGNADOS POR M. SCHELER}

Salgamos, ahora al paso de un posible equívoco: el sistema que propugna $M$. Scheler - entendido siempre en un sentido dinámico y al menos programáticamente - no es en absoluto «dualista».

Parte, es cierto, esta afirmación fundamental:

"La creencia en el Dios (de la Religión) no vive (ni siquiera como fe religiosa natural) a expensas de la metafísica, pero tampoco vive el conocimiento del Fundamento del mundo por obra y gracia de la religión»" ${ }^{47}$ :

No obstante pertenece a su convicción primera que:

«El Dios verdadero, no es tan vacío e inmóvil como el Dios de la metafísica... ni tan angosto y dinámico como el Dios de la mera fe» ${ }^{48}$.

Derivando, por esta causa, su pensamiento hacia la afirmación final:

«Tenemos que comprender, pues, que la más adecuada posesión de Dios, la máxima participación de nuestro ser en su ser, sólo puede alcanzarse por la visión conjunta, sin oposición y sin contradicción del Dios religioso y del Fundamento metafísico del mundo. No puede alcanzarse, pues, haciendo al Dios metafísico ni al religioso, medida del otro objeto intencional, respectivamente» ${ }^{49}$.

Según esto podríamos esbozar concretamente los sistemas impugnados por M. Scheler como dos extremos contrapuestos, presentándose la concepción scheleriana -al menos programáticamente - como punto intermedio entre ambos:

SISTEMAS DE IDENTIDAD

a) Religión = metafísica Tradiciónalismo

b) Metafísica $=$ religión Gnosticismo
SISTEMAS DE DUALIDAD

Religión $=/$ metafísica

a) Agnosticismo

b) Irracionalismo

SISTEMA DE CONFORMIDAD (M. Scheler)

La Religión y la metafísica se encuentran dentro de una unidad relacional ${ }^{50}$.

\footnotetext{
46. Ew. M. 287.

47. Ew. M. 135-136.

48. Ew. M. 138.

49. Ew. M. 137

50. Ew. M. 126-157.
} 
Resumimos, brevemente, el significado de este esquema:

1. Contra el tradicionalismo: La independencia de la Religión no ha de significar dominio absoluto de la misma.

M. Scheler destaca en principio los méritos de la corriente «tradicionalista» de la que - como veremos más adelante - no está lejano:

a) El ser reacción consciente - aunque unilateral - contra la filosofía de la llustración y su "teología natural» en la que no se daba ningún campo a la religión positiva;

b) El poner de relieve la dimensión comunitaria de la religión frente al individualismo solipsista protestante.

Sin embargo, no ignora que el tradicionalismo es un «sistema de ideas que exagerá la independenciạ de la Religión, convirtiéndola en dominadora absoluta, no correspondiendo esto ni a la esencia de la Religión ni a la de la filosofía» ${ }^{51}$.

El tradicionalismo niega, prácticamente, la espontaneidad del conocimiento humano haciendo del hombre "un être essentiellement enseigné», precisamente por la Religión, siendo la metafísica un epifenómeno de la misma ${ }^{52}$.

\section{Identidad parcial: teología escolástica}

Gracias a los estudios de K. Eschweiler, no desconoce M. Scheler las diferencias esenciales que separan, el verdadero tomismo medieval de su racionalización en la época de la contrarreforma; sin embargo, la teología natural "escolástica» que en $M$. Scheler se identifica con «tomista», cuenta en su «haber» los siguientes errores:

a) Diluir la religión natural en la teologia natural;

b) Convertir una pura concordancia (conformidad) de la metafísica y de la Religión en una identidad parcial en favor de la metafísica;

c) Denegar a la Religión la capacidad de fundamentarse a sí misma.

\section{Identidad total: sistemas gnósticos}

En la época de la llustración alcanza el proceso de la emancipación de la razón su punto cumbre. La razón se convierte en medida y norma de todo, incluso de lo Religioso. La esfera de esto, llega a ser una función parcial de la conciencia humana. Siendo lo Eterno, mero producto de la propia conciencia o la misma conciencia en el hombre.

Hegel es el exponente supremo de los sistemas gnósticos de la identidad

51. Ew. M. 134.

52. Cfr.: Franco, A., La Première réaction systématique de l'épiscopat belge contre l'enseignement du traditionalisme à l'Université de Louvain, Louvain: Nauwelaerts 1951. 
al definir la filosofía "como saber absoluto en forma conceptual» y la religión como "saber absoluto en forma de representación»" 53 .

Todo sistema gnóstico desconoce lo diferencial de la Religión, confunde su esencia: la Religión (tanto natural como positiva) es considerada como una etapa inferior del conocimiento metafísico. Se convierte la Religión en metafísica pero de segunda clase. Es una metafísica en símbolos e imágenes. En el horizonte gnóstico, pues, la metafísica es «la Religión de los filósofos» y la Religión» es la metafísica de las masas» ${ }^{54}$.

\section{Sistemas dualistas}

Kant intenta clavar hitos en las fronteras del «saber» para dar un espacio a la "fe». La especulación no puede, para él, proporcionar una solución definitiva a los temas inevitables de la razón pura «Dios, libertad, inmortalidad» ${ }^{55}$. El filósofo de Königsberg está plenamente convencido de que «la razón no consigue nada, ni por un camino (el empírico) ni por otro (el trascendental), de forma que en vano extiende sus alas para ir más allá del mundo de los sentidos con sólo el poder de la especulación» ${ }^{56}$.

Sin embargo la Crítica de Kant no permanece únicamente en un plano negativo.

En el capítulo titulado: "Crítica de toda teología basada en los principios especulativos de la razón» ${ }^{57}$, Kant distingue una teología que es producto exclusivo de la misma razón (Theologia naturalis) y una teología cimentada en la revelación (Theologia revelata).

La primera la subdivide a su vez en teología trascendental y natural. Aquélla "se imagina» su objeto por medio de conceptos trascendentales («ens originarium, realisimum, ens entium»), ésta a través de un concepto tomado de la misma naturaleza (el alma humana como «inteligencia suprema»).

La teología racional está basada en los principios especulativos de la razón y es precisamente contra esta teología contra la que se vuelve Kant: «Afirmo que todos los intentos de usar de una manera exclusivamente especulativa la razón dentro del càmpo de la teología, han de ser inútiles y - según su estructura interna - absolutamente nulos» ${ }^{58}$.

Nos conformamos sólo con asomarnos a la compleja problernática kantiana. Para Kant, es incapaz la especulación de llegar a Dios, dado que solamente se tiene "conceptos» e «intuiciones» de aquello que pertenece al mundo fenoménico.

Para Kant, Dios puede ser solamente un postulado de la razón práctica

53. Ew. M. 128.

54. Ew. M. 127ss.

55. Kant, Kritik der reinen Vernunft, B 7.

56. I.c., B 619 .

57. Kant, Kritik der reinen Vernunf, B. 659-670.

58 . I.c.. B, 664 . 
- «sin un Dios y sin un mundo invisible ahora, pero esperado, son las maravillosas ideas de la moralidad digna de aplauso y admiración, pero nunca resortes eficaces de propósitos»- o un supuesto del juicio teleológico ${ }^{59}$.

Fundamentalmente Kant impugna con su concepción la actitud optimista de la llustración, abriendo como una profunda valla entre la urazón pura» y la "razón práctica», entre el "ser» y el "deber-ser», entre la "ratio» y la "fides», entre el «saber» y el «creer».

De Kant precisamente brotarán las corrientes dualistas tanto irracionalistas como agnósticas. En adelante se aspirará a concebir la religión de una manera ateórica (Jacobi-Schleiermacher) o será rechazada como pura fantasía y producto de las facultades anímicas (Marx y Feuerbach, Positivismo y Pragmatismo).

\section{SISTEMA DE CONFORMIDAD}

Frente a todos los sistemas de identidad y de dualidad, presenta $\mathrm{M}$. Scheler el «sistema de conformidad».

La filosofía y la religión son realmente distintas entre sí. Ambas gozan de independencia y autonomía, respectivamente.

Sin embargo, esta diferencia esencial no significa «desvinculación absoluta». El término "conformitas» es el que define su mutua relaciọn.

Con esta "conformidad» echa $M$. Scheler un puente entre la identidad y la dualidad. No se da ni ésta ni aquélla, porque la conformidad evita la separación omnímoda dentro de una distinción real de ambas. La metafísica y la religión forman una unidad relacional, que manteniendo la diferencia esencial de ambas, se basa en una intrínseca relación: "Lo primero que ofrece el sistema de conformidad es no desmembrar (auseinanderreissen) la ciencia de la fe, no lesionar el principio: "Gracia perficit naturam, non negat», permitiendo, pues, la coexistencia de la unidad de la religión y de la unidad de la metafísica» ${ }^{60}$.

Resumimos brevemente estas dos ideas fundamentales del pensamiento de M. Scheler; brevemente impuesta por el carácter esquemático de sus afirmaciones.

\section{Diferencias fundamentales entre religión y filosofía}

Lo distinto de ambas aparece de una forma palmaria considerando:

a) Su objeto intencional:

Teniendo presente su objeto ambas formas son intencionalmente distintas, aunque materialmente idénticas: «No existe un Dios natural y un Dios de la revelación, sino sólo un Dios» ${ }^{61}$.

59. I.c., B. 841 .

60. Ew. M. 142.

61. Ibd. 
Sin embargo, el Dios de la metafísica es el «ens a se» mientras que el Dios de la religión es el "Summum Bonum»; no sólo es el principio fundamental del cosmos; él ha creado más bien el mundo y está presente en él con su amor infinito $y$ personal.

El Dios de la filosofía es lo Absoluto y Trascendente considerado «sub ratione entitatis». El Dios de la Religión aparece «sub ratione divinitatis» como inmanente a las cosas y a las personas. Podría afirmarse que es necesario salirse del campo filosófico para adentrarse en el campo de la religión, donde habita el Dios de Abrahám, de Isaac y de Jacob.

A pesar de la distinción en el aspecto formal, el Dios de la filosofía y el de la religión es "uno e idéntico». De aquí concluye $M$. Scheler que el «conocimiento religioso es imperfecto si no está fundamentado (untermauert) filosóficamente; de la misma forma que el Dios de los filósofos es demasiado "vacío» si no está completado (durchdacht) por la religión. Ambas perspectivas proporcionan la verdadera imagen de Dios.

b) La fuente de la religión es «la revelación divina», la de la filosofía la capacidad discursivo-racional.

La filosofía es «construcción» espontánea, siendo la actitud religiosa eminentemente receptiva: es una reacción a una acción originaria de Dios, una respuesta en "engagement» personal a la palabra de Dios: "Todo saber religioso acerca de Dios es un saber a través de Dios" ${ }^{62}$.

La verdad religiosa es una verdad-encuentro. La religión como encuentro implica la libertad de los que realizan ese encuentro y la revelación que proviene de Dios, presuponiendo siempre ésta la abertura del hombre a Dios y de Dios al hombre.

La verdad filosófica es «arquitectura» humana levantada por la espontaneidad constructora de la razón.

c) La religión tiende esencialmente a la «salvación del hombre en la existencia comunitaria con Dios, tiende a la «deificación» (Vergottung) del hombre» ${ }^{63}$.

La filosofía brota de una "admiración» como nos dice Platón y aspira al conocimiento intelectual de su objeto. De esta tendencia a un fin específico emerge el que la forma social de la religión sea la Iglesia y la de la filosofía la Escuela y no precisamente en el sentido de «una representación de bienes de fe que hay que aceptar obligatoriamente por la creencia en ellos» sino de «instrucción en una teoría metafísica»" ${ }^{64}$.

d) En cuanto la forma de expresión, la religión habla en símbolos, mientras que la filosofía en conceptos abstractos. Toda verdad religiosa es una verdad simbólica en oposición a la verdad conceptual. A Dios sólo le podemos conocer por medio de las expresiones inadecuadas de las creatura. El

62. Ew. M. 143.

63. Ew. M. $\cdot 130$.

64. Ew. M. 129 
«videre ad faciem» se encuentra más allá de todo lo creado. M. Scheler recurre a una expresión plástica tomada del Deuteronomio: No podemos ver a Dios «de frente» sino "de espaldas» (auf den Rücken), y es que en todas las expresiones sobre Dios es mayor la "dissimilitudo" que la «similitudo».

e) El tipo representativo de la religión es el santo, mientras que el de la filosofía es el sabio. Bien podría hacerse aquí a M. Scheler aquella famosa corrección de Sócrates fijada por Platón en el "Fedro»: «El llamarle sabio, Fedro, me parece algo excesivo que sólo a la divinidad corresponde. En cambio el llamarle filósofo, amante de la sabiduría, le estaría más en consonancia y mejor acomodado".

Ambos tipos son posibilidades auténticas de la existencia humana para M. Scheler.

En el sabio lo específicamente posible del hombre llega a su plenitud; es el punto cumbre de la gráfica del desarrollo humano.

En contraposición, la grandeza del santo radica en su pequeñez, que de cara a Dios cristaliza en el sentimiento de humildad. El santo está seliado por la virtus infirmitatis; pero en él se manifiesta Dios como en un milagro ya que aparece en la paradoja de la pequeñez y pobreza humana. El santo es un «signum Dei», un «kerygma» de Dios.

\section{Unidad relacional entre religión y filosofía}

A pesar de todas estas diferencias fundamentales existe una íntima relación entre religión y filosofía.

Aunque el objeto intencional sea distinto en ambas, en su vertiente material - como hemos visto - es idéntico:

"No existe un Dios natural y un Dios de la revelación, sino un solo Dios».

La metafísica busca a Dios «sub ratione entitatis», la religión se arrodilla ante Dios que aparece "sub ratione divinitatis".

El punto de mirada es distinto, pero no aquello que se contempla.

El conocimiento religioso es imperfecto si prescinde de la dimensión metafísica, y el Dios de la filosofía tampoco es completo si prescinde de la vivencia religiosa: "El Dios verdadero no es tan vacío ni estático como el Dios de la metafísica, ni tan angosto (eng) y dinámico como el Dios de la mera fe». La posesión adecuada de Dios es como el torrente que corre por entre ambas riberas.

Existe, por otra parte, una simbiosis - resultado de su relación intrínseca - entre el acto del conocimiento religioso y del metafísico.

llustramos el pensamiento scheleriano a este respecto por la relación existente entre teologia y fe:

La fe hace posible la teología, pero la teología, por su parte, ancla a la fe. La fe es el fundamento interno de la teología, y la teología es a su vez condición extrínseca de una creencia profunda.

En este sentido es para $M$. Scheler, la religión, el fundamento interno de 
la metafísica y la metafísica, condición extrínseca de la religión. La posesión religiosa de Dios posibilita la pregunta sobre el "trasfondo» (Hintergrund) del ser. $Y$ el conocimiento metafísico de este «trasfondo» profundiza y se adentra en el horizonte de lo Absoluto.

\section{CONSECUENCIAS INMEDIATAS}

Sobre este horizonte se abre el intento programático de $M$. Scheler: no se propone salir de sí mismo para trepar por las estructuras del cosmos, hasta llegar a Dios.

No construye ningún sistema de categorías aprióricas de lo Religioso para analizar los límites de su posibilidad. Prescindiendo del proceso discursivoracional y no interesándole la "quaestio iuris», se «instala inmediatamente»" ${ }^{65}$, en Dios mismo, que encuentra como Eterno en el núcleo más profundo de su ser por medio del "sentido religioso trascendente» ${ }^{66}$.

Se da en M. Scheler, según esto, una prioridad y originalidad del conocimiento religioso con respecto a las demás clases de conocimiento, $y$ en concreto con relación al metafísico ${ }^{67}$. Este tendrá que volver sobre aquél ${ }^{68} \mathrm{si}$ quiere invocar el derecho a la existencia.

\section{Las pruebas de la existencia de Dios}

Para entender con más claridad la actitud scheleriana analicemos - brevemente - este tema concreto. - Las pruebas de la existencia de Dios - que, como se sabe, constituyen el "corpus» de las teodiceas tradicionales, no superan, en $M$. Scheler el plano de lo marginal.

Para M. Scheler del mismo modo que de lo inorgánico no puede llegarse a lo orgánico, tampoco se puede trepar de la esencia del mundo a la de Dios: la diferencia es mayor.

No se piense con esto que $M$. Scheler niega el principio de causalidad ${ }^{69}$, simplemente, lo estima insuficiente ${ }^{70} \mathrm{e}$ innecesario ${ }^{71}$.

65. Soz. Welt. 110 .

66. Symp., 32.

67. Ew. M. 148.

68. Nachl. 182-183.

69. «El principio de causalidad, confundido por Kant con el principio de la regularidad de los fenómenos, según una norma de orden cronológico, es un principio universal y evidente» (Ew. M. 273).

70. «Digo con toda libertad: si yo quisiera deducir por una inferencia causal la idea y la existencia de Dios, de la conformidad y existencia del mundo, tal como yo lo conozco, y no de un originario contacto personal y vivencial del núcleo de mi persona con una bondad y sabiduría sagradas, me bastaría, ciertamente, aun en el caso de que todo el resto del universo resplandeciera en paz, dicha y armonía, la existencia de una única sensación de dolor... para rehusar mi reconocimiento, a un Creador infinitamente bondadoso de este mundo" (Soz. Welt. 41).

71. Ya que sólo podría constatar, lo que se ha afirmado por una vivencia personal. 
En consecuencia con esta actitud inicial, corresponde a las pruebas de la existencia de Dios el valor de udescribir en una formulación artificial y racional, los caminos por los que el hombre, - que ya ha afirmado la existencia de un «ens a se» infinito y espiritual, por medio de una fuente de conocimiento totalmente independiente de estas pruebas - , se explica de una manera ulterior, las múltiples relaciones, que puede tener Dios con el mundo y con su constitución esencial» 72 .

Es fundamental, pues, en el pensamiento de M. Scheler, que en el horizonte de lo "Divino", el hombre solamente puede recibir, aceptar, descubrir algo que originariamente ya estaba allí. De aquí brota la afirmación: «Si lo Divino y todo lo que tiene relación esencial con él, solamente puede "darse» en actos de la esencia del acto religioso, la explicación de una esfera ónticosobrenatural no puede proceder primordialmente por "pruebas», que toman su punto de partida en hechos de experiencia extra-religiosa, sino mediante el despertar (Weckung) y excitar (Erweckung) los actos religiosos en el mismo espiritu hurnano» ${ }^{73}$.

Con esta actitud realiza $\mathrm{M}$. Scheler un giro radical. Las pruebas de la existencia de Dios, no son el fundamento de lo religioso, sino al contrario. Por eso cuando se hunde la cosmo-visión teocéntrica, parecen taradas en su valor.

Dos prejuicios, confiesa M. Scheler, pueden obnubilar este pensamiento.

a) un concepto demasiado pobre del ámbito de la experiencia, y

b) la ausencia de ideas claras «sobre los límites de la demostrabilidad, dentro de las esferas del 'saber' $y$ 'conocer' $)$.

Sobre el primer punto afirma $M$. Scheler: "Lo dado es inmensamente más abundante que la parte de lo dado que corresponde de un modo estricto a la experiencia sensible») ${ }^{74}$.

En cuanto al segundo prejuicio, estima que todo juicio, ciertamente, necesita una justificación, pero sólo dentro de ciertos límites esta justificación se identifica con la «prueba». Basado en esta convicción delimita los campos:

a) "No tiene ningún sentido "demostrar» (beweisen) la realidad o evidencia. Son demostrables las proposiciones sobre lo real, pero no lo real mismo" ${ }^{75}$.

b) «Solamente es demostrable una afirmación ya encontrada. Esto es universalmente válido, siempre que el objeto a demostrar no brote en principio de un método deductivo"s ${ }^{76}$.

c) «La esencia y la existencia de Dios se puede «descubrir» (aufweisen) o «re-descubrir» (nachweisen) pero no «demostrar» en sentido estricto» $\pi$.
72. Ew. M. 15.
73. Ew. M. 249.
74. Ew. M. 250
75. Ew. M: 252.
76. Ew. M. 253
77. Ew. M. 254 
M. Scheler no niega, sin embargo, con su actitud toda posibilidad de las pruebas de la existencia de Dios. Se movería entonces dentro de un agnosticismo metafísico. Únicamente se limita a designar su función concreta: la de "verificación», "constatación», "comprobación» de una realidad ya afirmada ${ }^{78}$.

Podríamos decir que aquí muestra $M$. Scheler el coeficiente histórico de S. Agustín y de B. Pascal que había escrito: «Tu ne me chercherais pas, si tu ne m'avais trouvé»" ${ }^{79}$.

Es fundamental para el entendimiento de la postura concreta de $\mathrm{M}$. Scheler sobre las pruebas de la existencia de Dios el hecho de moverse en el plano de lo inmediato, prelógico, de lo "dado», de lo presente. En este caso las preguntas sobre las garantías de esa existencia no representan ningún problema.

M. Scheler respondería, sin duda, que no hay mejor garantía que la misma presencia. Esta no puede demostrarse (beweisen) en el sentido de que se necesite todo un proceso para llegar a ella, pues se está en ella. Sólo se puede "descubrir» (aufweisen) al "manifestarse por primera vez» o «re-descubrir» (nachweisen) en el sentido de "enseñar el camino para re-encontrar lo que se había ya encontrado" ${ }^{80}$.

M. Scheler prescinde, pues, de todo momento gnoseológico. Para él el criterio de la luz es la luz misma; y si no ve alguien la luz es porque sus ojos son de tierra o porque no quiere verla.

\section{La metafísica y la fenomenología de la religión}

El «sistema de conformidad» propuesto por M. Scheler no supera, en lo que respecta a su obra De lo Eterno en el hombre, la dimensión de lo meramente programático. Se reduce a una fenomenología de la Religión, completada con datos procedentes del área del conocimiento religioso ingenuo.

La razón de este proceder quizá se encuentre en que el momento metafísico es claramente infravalorado por M. Scheler: «Sabemos de antemano que toda afirmación metafísica: a) es siempre hipotética y b) nunca supera los límites de la mera probabilidad" ${ }^{81}$.

Este juicio negativo sobre los resultados de la metafísica emerge de una concepción especifica de la misma.

No entiende por metafísica el concepto tradicional que abarca tanto la «metaphysica generalis» como la «metaphysica specialis». Para él la ontología no es metafísica, es lo que llama "eidología ontológica» u "óntica esencial» (Wesensontik), que tiene carácter evidente y apriórico en cuanto es resultado de la intuición fenomenológica.

\footnotetext{
78. Ibd.

79. B. Pascal, Pensées. Texte de l'édition Brunschvicg, Paris: Garnier 1960, 212.

80. Ew. M. 251.

81. Ew. M. 300.
} 
Metafísica para él es sólo la «metaphysica specialis» y «su objeto último y supremo es el "fundamento del mundo...», lo absolutamente real... Toda metafísica está cargada (schwanger) de "mundo" y de contenido empíricoespiritual y tiende a mostrar cómo este mundo está radicado (eingewurzelt) en el "fundamento del mundo» (Weltgrund)»" 22.

La metafísica para M. Scheler es una construcción racional cuya posibilidad está fundamentada en estas dos fuentes:

a) La eidología

b) Los resultados de la ciencias positivas.

«Mais l'ontologie eidétique n'est pour la métaphysique qu'un «tremplin» - elle n'est pas déjà la métaphysique elle-même. Comme celle-ci est en effet un savoir du réel (Realwissen), elle ne peut s'appuyer uniquement sur des connaissances ne concernant que les essences: il faut qu'en même temps elle soit fondée - et c'est là sa deuxième prémisse ou sa deuxième composante"dans toute la richesse de la réalité effective contenue dans l'expérience de la vie, dans les sciences et dans l'histoire». La synthèse notamment des résultațs obtenues par les sciences positives tournées vers la réalité effective et des résultats de la philosophie première orientés vers l'essence définit la tâche de la metaphysique en tant que science qui à la fois transgresse les limites de l'expérience et reste connaissance de la réalité» ${ }^{83}$.

La eidología, poniendo fuera de acción lo real, despliega un saber a priori de lo esencial. Sus verdades son válidas para todos los mundos posibles; estas verdades son precisamente la premisa «mayor» de las inferencias metafísicas.

Los resultados de las ciencias positivas sobre lo real contingente suministran la premisa «menor». De aquí que el carácter hipotético y probable de la metafísica sea en $\mathrm{M}$. Scheler pura consecuencia de su concepción original de la misma.

A pesar de la infravaloración evidente de los resultados de la metafísica, M. Scheler la asigna la posibilidad de:

a) preparar el camino al conocimiento «religioso» de Dios ya que «toda conciencia limitada - en cuanto existe sin una revelación de Diostiene necesariamente una metafísica, e.d., tiene la convicción íntima de una esfera que estima absoluta y que se presenta como la síntesis de todas las esencias limitadas" ${ }^{84}$,

b) estimular al acto religioso, al estar radicada - como necesidad - en la naturaleza del hombre.

De una manera ulterior la metafísica nos proporciona dos afirmaciones sobre Dios, gnoseológicamente evidentes, pero carentes de contenido mate-

82. Ew. M. 145.

83. M. Dupuy, La philosophie de la Religión chez M. Scheler, Paris: P.U.F., 1959. 73.

84. Ew. M. 207 
rial, al poseer un carácter eminentemente formal: «ens a se» $y$ «prima causay). ${ }^{85}$.

Es importante reseñar que M. Scheler, en principio, -concretamente en De lo Eterno en el hombre - se limita a una fenomenología de lo Divino, completada, por decirlo así, con datos procedentes del conocimiento religioso.

Sólo en sus últimas obras -Cosmovisión filosófica y El Puesto del hombre en el cosmos - aparece su concepción metafísica, desarrollando así el «sistema de conformidad» en su totalidad.

Su filosofía final está, pues, incluida programáticamente al menos -a este nivel de nuestra investigación no podemos ir más lejos en nuestras afirmaciones - en el «sistema de conformidad» propuesto en De lo Eterno en el hombre.

La fenomenología de la religión inmersa en el mundo de lo esencial tendrá como temática la "deitas», de cuyo momento existencial se prescindirá en absoluto, aunque $M$. Scheler entremezcle datos obtenidos por el conocimiento religioso ${ }^{86}$ y afirme su existencia, aunque sólo desde esta perspectiva.

La metafísica, que se apoya como en una de sus premisas en la eidología pero que como «Realwissenschaft» tiene por objeto lo "absolutamente real en cuanto radicado en el Fundamento del mundo», junto con la "deitas» (Geist) presentará el principio frontal de lo real que es el «impulso» (Drang), apareciendo así el dualismo ontológico final como simple consecuencia y no como «ruptura» (Bruch) con el pensamiento anterior.

La fenomenología de la religión en $M$. Scheler se levanta sobre estos dos pilares:

\section{A) EIDOLOGÍA DEL OBJETO RELIGIOSO \\ B) EIDOLOGÍA DEL ACTO RELIGIOSO}

Esta será concretamente la vertebración de esta nuestra Segunda Parte. El objeto religioso se da en la región apriórica de la «Esfera del Absoluto». A ésta la corresponde una "óntica esencial de lo Divino».

Ahora bien, M. Scheler distingue entre «consistencia» (Bestand) y «contenido» (Gehalt) de la «Esfera del Absoluto», estando determinado su "contenido» por las «diferentes formas de automanifestación» de lo Divino.

Subrayemos aquí la transición verificada por $M$. Scheler, que de una

85. Ew. M. $16,5$.

86. Los datos obtenidos por el conocimiento religioso en $\mathcal{M}$. Scheler están teñidos de una indiferenciación absoluta entre el orden natural y el sobrenatural e.d., entre lo perteneciente al hombre "de iure» y «de facto», al estar insertado en el orden de la gracia. Como hemos apuntado anteriormente, esta indiferenciación tiene como condicionamiento «el augustinismo que lleva la impronta de la época de Nietzschen y se proyecta - como veremos - de forma clara en las complejas distinciones scheleriañas sobre le «revelación positiva». 
perspectiva fenomenológica - circunscrita a la «consistencia» (Bestand) de la «Esfera del Absoluto» - pasa a la perpectiva del conocimiento religioso con cuyos datos «llena» aquélla, dando entrada así a una serie de elementos extrafenomenológicos que, sin embargo, hemos de considerar ya que pertenecen a la estructura total del estudio del «Tema de Dios» en el pensamiento de $\mathbf{M}$. Scheler.

Según esto tenemos la siguiente división como objeto inmediato de nuestra investigación:

EIDOLOGIA DEL

-OBJETO RELIGIOSO

- CON. RELIG.
A) LA ESFERA DEL ABSOLUTO

B) ONTICA ESENCIAL DE LO DIVINO DIVERSAS FORMAS DE AUTOMANIFESTACIÓN DE LO DIVINO

Ahora bien, para mejor comprensión de la eidología del acto religioso, hemos de considerar primeramente la eidología de los actos en general, para estudiar luego la eidología del acto religioso en especial.

Al existir una correlación esencial entre la esfera de los actos y la de los objetos, participan los actos de las particularidades de los objetos. De aquí que al distinguir $M$. Scheler en la "Esfera del Absoluto» la "consistencia» (Bestand) y el "contenido» (Gehalt), podamos también diferenciar en el acto religioso una "consistencia» y un "contenido» (Inhalt), de donde partirá nuestra consideración final sobre la uactitud fenomenológica scheleriana y el problema de la existencia de Dios».

El objeto de investigación será, pues, aquí:

-EIDOLOGÍA DE LOS ACTOS EN GENERAL

- EIDOLOGIA DEL ACTO RELIGIOSO

- ACTITUD FENOMENOLÓGICA SCHELERIANA Y EL PROBLEMA DE LA EXISTENCIA DE DIOS ${ }^{87}$.

87. Queremos advertir que el análisis fenomenológico de la «persona» no le insertamos en esta Segunda Parte. La razón fundamental estriba en que M. Scheler, desde un principio, divide al hombre en dos sectores ónticos irreductibles: el "homó naturalis» y el "hombre-persona», insertando a éste en el mismo núcleo de la divinidad. La trascendencia de esta distinción ontológica para el objetivo de nuestra investigación nos hace colocar el análisis fenomenológico de la upersona» en la Tercera Parte a fin de darla la estructuración más completa posible. 


\section{CAPITULO SEGUNDO}

\section{EIDOLOGIAA DEL OBJETO RELIGIOSO}

\section{LA ESFERA DEL ABSOLUTO}

Después de haber reseñado la doctrina scheleriana de las esferas, intentamos adentrarnos ahora de una manera concreta en la «esfera del Absoluto».

Esta hay que concebirla como el trasfondo y el horizonte apriórico sobre el que aparecen los «objetos absolutos» ${ }^{88}$. Toda pregunta ulterior sobre los contenidos concretos de esta esfera, ha de suponerla ya dada, de lo contrario se intentaría levantar algo sobre lo sin-base.

\section{DESCRIPCIÓN FENOMENOLÓGICA DE LA ESFERA DEL ABSOLUTO}

M. Scheler entiende por "esfera del Absoluto»:

«El ser totalmente sin forma, ni en cuanto acto, ni en cuanto al serobjeto (ser-resistencia, respectivamente), ni en cuanto al valor, ni en cuanto al ser-ahí, ni en cuanto al ser-así, ni en cuanto a la naturaleza o ser psíquico, ni incluso, en cuanto al ser-algo o no-ser-algo (=nada); aquel ser indiferenciado por excelencia, que trata Plotino de describir como "puro ser" ${ }^{89}$.

Observamos aquí la censura de formalismo que le echan en cara ciertos intérpretes a M. Scheler ${ }^{90}$. Estimamos, sin embargo, que, al menos en esta vertiente de su pensamiento - objetivamente hablando - y dada su fundamentación plotiniana, está excluido todo formalismo, al menos en un orden intencional.

Al considerar la descripción fenomenológica scheleriana de la Esfera del Absoluto, brotan, casi imperceptiblemente, aquellas palabras de Plotino:

88. Eth. 125.

89. Nachl. 251.

90. A. Trost, Das Sein der Werte. Eine Untersuchung zur Ontologie der Werte bei M. Scheler und N. Hartmann, 114, G. Scheler, Der emotionale Apriorismus. Versuch einer Auseinandersetzung mit $M$. Scheler, 95.

I. Heidemann, Untersuchungen zur Kantritik Schelers 1 aa 
«Dios no tiene forma, ni aun inteligible... existe en sí mismo uniforme, más aún informe, anterior a toda forma, movimiento o reposo ${ }^{91}$.

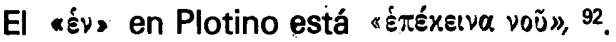

Estrictamente hablando, no sería exacta la interpretación de M. Scheler, pues Plotino concibe al 〈 $\alpha$ Év $\rangle$ 〉 como trascendiendo al ser mismo. Basado en esto afirma W. R. Inge que Plotino designó lo Divino como $« \varepsilon \dot{\varepsilon}\rangle s$ porque le faltaba la expresión «cero» ${ }^{93}$.

Esta concepción plotiniana tiene una proyección completa sobre la teología negativa. Como un caso concreto tenemos a Pseudo-Dionisio, que

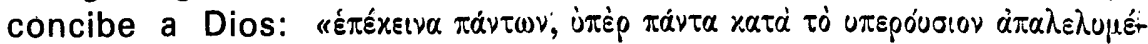
vos» 94.

La Esfera del Absoluto pàra M. Scheler, está también más allá de todo pensamiento $y$ de toda determinación categorial de modo que la razón no puede agotarla en ningún modo: «Es evidente que al ser 'puro ser' es contradictorio poderle pensar totalmente» ${ }^{95}$.

\section{2. «CONSISTENCIA» Y «CONTENIDO»}

La Esfera del Absoluto, en su ser apriórico, originario y primero es afirma da repetidas veces por $M$. Scheler ${ }^{96}$, asegurando que es "completamente evidente ${ }^{97}$.

En un dogmatismo rayano con lo intolerable para un fenomenólogo llega $M$. Scheler incluso a afirmar: «querer investigar una evolución del hombre hacia lo religioso, en general, es un problema sin sentido. Igual que el problema del original del objeto religioso en general y la cuestión del origen de la representación del objeto religioso como tal» ${ }^{98}$. Es, pues, más radical que $\mathrm{S}$. Agustín y el augustinismo medieval en quienes encontramos con frecuencia diversas afirmaciones sobre la génesis de lo Religioso en el hombre. De manera ulterior, rechaza $M$. Scheler, toda pregunta sobre el criterio de verdad. Este incluye ęn su ésencia el problema «del eterno-otro" ${ }^{99}$.

El carácter originario y primero de la esfera del Absoluto, está primordialmente en su auto-manifestación y evidencia: «la auto-manifestación apriórica excluye de sí toda pregunta sobre el origen y sobre la validez. La primera por

91. Eneadas, ed., de P. Henry y H.R. Schwyzer 1951, VI, 9,3.

92. I.c., V,4,2.

93. The Philosophy of Plotinus, Gifford Lectures, Longmans 1918, 107.

94. Cfr.: Migne, Patrologiae Cursus completus, Series I: Ecclesia Graeca, Paris 1857 - 1912, III, $869 \mathrm{D} ; 872 \mathrm{C}$.

95. Nachl. 251.

96. Ew. M. 252.

97. Wi. Ges. 374.

98. Ew. M. 170.

99. Nachl. 382 
ser originaria, la ủltima, porque la auto-manifestación y la evidencia son ideales cognoscitivos, que están en una vertiente anterior a la misma verdad y falsedad) ${ }^{100}$.

Ahora bien, dentro de la esfera del Absoluto, como se advirtió antes, hay que distinguir dos momentos: la consistencia» (Bestand) y el "contenido» (Gehalt).

Pertenece a lo esencial del hombre ${ }^{101}$ la «consistencia» de una esfera del Absoluto al estar dada de una manera evidente y fundamental a la conciencia humana, sin embargo «puede tenderse a una esfera, que es en sí misma relativa como si fuese absoluta» ${ }^{102}$. El contenido concreto puede ser, por tanto, un idolo" 103

En este caso se encuentra el hombre ante una «ilusión» (Täuschung): "Lo esencial de la ilusión es que se da intuitivamente algo, que no está propiamente allís ${ }^{104}$.

La «ilusión», sólo se da, según esto, en el terreno intuitivo, dándose en el plano conceptual el «error». Lo contrapuesto a lo verdadero es aquí lo «falso», allí lo "aparente».

De aquí emerge una norma importante de pedagogía religiosa que nos hace más cercano el mundo religioso de $\mathrm{M}$. Scheler: Una actitud «lógica» no puede tener en este campo validez decisiva. Cuando «llena» la esfera del $A b$ soluto un «ídolo», sólo nos puede ayudar el método del "desengaño» (Enttäuschung) y no el deductivo-șilogístico basado en una argumentación racional.

La "consistencia» de la esfera del "Absoluto» y el "contenido» de la misma son dos momentos que hay que distinguir entre sí: el primero pertenece a una perspectiva fenomenológica, brotando el segundo de un conocimiento religioso extrafenomenológico.

El «llenarse de contenido» la esfera está abierto incluso a una pregunta genética: «Surge un problema nuevo... cuando se pregunta sobre qué esfera, independiente e irreductible, está ya llena de contenido" ${ }^{105}$.

Hay que insistir, sin embargo, en que para M. Scheler la "consistencia» de la esfera del Absoluto no puede interpretarse en sentido formal al ser el trasfondo (Hintergrund), el horizonte apriórico sobre el que se recortan sus determinaciones ulteriores.

La esfera del Absoluto está constituida de tal forma que «si la corresponde algo real, no puede ser aprehendido por actos espontáneos, sean de la clase que sean, sino exclusivamente. por una auto-manifestación»" ${ }^{106}$.

\footnotetext{
100. Ibd.

101. Ew. M. 261.

102. Nachl. 251.

103. Nachl. 226.

104. U.d.W. 216.

105. Stell. 87.

106. Nachl. 200.
} 
Solamente es posible, pues, para M. Scheler, el «llenarse» la esfera del "Absoluto» mediante una revelación del mismo ${ }^{107}$ ya que, en último término, «todo saber acerca de Dios se da únicamente a través de él» ${ }^{108}$.

La auto-manifestación de Dios representa, pues, la dimensión objetivoconcreta de la esfera del Absoluto en cuanto que la llena de contenido.

Al referirnos ahora a la doctrina scheleriana de la revelación no es nuestro propósito precisamente tratar este problema teológico en sí mismo. Sólo intentamos poner en el pensamiento diseminado de $\mathrm{M}$. Scheler orden y estructura para ganar una imagen de su «objeto religioso» lo más clara y fiel que nos sea posible.

107. Ew. M. 345.

108. Ew. M. 245. 


\section{CAPITULO TERCERO}

\section{DIFERENTES FORMAS DE AUTORREVELACIÓN DE LO DIVINO}

\section{LA REVELACIÓN COMO ORIGEN DEL CONOCIMIENTO RELIGIOSO}

Subrayemos, desde un principio, que M. Scheler abandona sin duda su actitud fenomenológica al tratar de las distintas formas de auto-manifestación de lo divino, pasando a la perspectiva noética de la "experiencia religiosa».

Su estudio, sin embargo, contribuye a la exposición adecuada del «Tema de Dios» en su pensamiento. De aquí que las tratemos en este contexto.

«Puesto que Dios es según su esencia exclusivamerite persona, la primera condición fundamental de su posible conocimiento general es la automanifestación y no solamente de su contenido real total o parcial, sino de su serrealı) ${ }^{109}$.

Ahora bien, para M. Scheler, no depende de la realidad de Dios el que tengamos posibilidad de saber acerca de él, depende más bien de la esencia de la realidad de Dios, depende de la infinitud de amor de la persona infinita.

La automanifestación se funda, pues, en el amor infinito de la esencia de Dios.

En contraposición a los actos de conocimientos espontáneos, la revelación es «una especie fundamentalmente distinta de la posible producción de evidencia» ${ }^{110}$; esta posible producción de evidencia, se apoya en último término en que "todo saber acerca de Dios es saber a través de Él»" ${ }^{111 .}$

\section{DIVISIÓN DE LA REVELACIÓN}

M. Scheler distingue una triple revelación: natural, positiva y una última que coloca uentre el conocimiento racional, espontáneo-mediato y la revelación positiva» ${ }^{112}$.

109. Nachl. 186.

110. Ew. M. 143.

111. Ew. M. 245.

112. Ew. M. 21. 
"En la medida en que lo Divino se presenta y se muestra en cosas, sucesos, órdenes que pertenecen a la realidad natural, accesible en principio a todos y a la realidad psíquica e histórico-social, hablamos de revelación natural, cuyo correlato subjetivo es la religión natural. A la inversa: en la medida en que se presenta o anuncia por medio de la palabra y mediante personas, los «homines religiosi» en el sentido más eminente de la palabra, hablaremos de revelación positiva ${ }^{115}$.

Esta la subdivide, a su vez, en una forma de revelación que va destinada a la persona como miembro de un todo solidario, llamada revelación en sentido estricto y "una que se realiza en la persona singular»-designada con los nombres de «iluminación» y «gracia»- ${ }^{114}$.

Como hemos apuntado con anterioridad, el pensamiento de M. Scheler, por lo que toca a la revelación "positiva», es un tanto confuso; se da en él una absoluta indiferenciación entre lo natural y sobrenatural, estando abierto, por esto, a equívocos. En alno de los puntos subsiguientes dilucidaremos su pensamiento a este respecto.

En las formas descritas de revelación aparece lo Eterno en el tiempo, como realidad infinita y concreta. Este «aparecer» puede ser interpretado solamente en el sentido scheleriano de «llenar la esfera del Absoluto, con aceptaciones determinadas y contenidos de fe" ${ }^{115}$. La revelación en sentido activo, existe - libremente, es cierto- desde siempre, como algo no-oculto, como

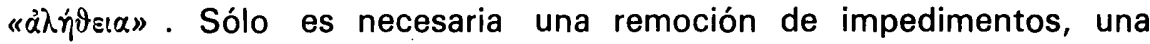

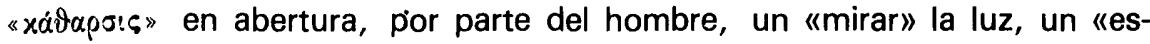
cuchar» la palabra por parte de la persona humana-finita.

Antes de pasar a un análisis concreto de las formas de automanifestación de lo divino, creemos conveniente considerar dos puntos que nos ayudarán sin duda en la comprensión del contenido del pensamiento scheleriano:

\section{Conexión esencial entre "persona» y «revelación»}

No intentamos aquí tratar de conceptos de persona en $\mathrm{M}$. Scheler puesto que será objeto especial de estudio en otro lugar de nuestra investigación.

Nos importa destacar únicamente que la revelación de Dios se apoya fundamentalmente en su ser "personal».

Sólo la persona, en cuanto tal, puede «callar» ${ }^{116}$, sólo puede ser conocida en cuanto se deja conocer por una auto-manifestación personal.

El hecho de la revelación divina o humana es posible porque una persona - divina o humana - quiere darse a conocer:

113. Ew. M. 157.

114. Nachl. 230.

115. Stell., 87.

116. Ew. M. 331. 
"La persona de Dios se substrae a toda especie de conocimiento racional espontáneo por parte de seres finitos, no por los llamados límites de la potencia cognoscitiva, sino porque pertenece a la esencia objetiva misma de una persona espiritual el que su existencia, si existe, sólo pueda conocerse mediante una auto-manifestación" ${ }^{117}$.

El ser personal de Dios y su revelación tienen, pues, una conexión esencial recíproca: "Solamente puede ser cognoscible a los hombres un Dios personal por medio de la revelación («gracia» o «iluminación») ${ }^{118}$. Esto tiene su explicación en que la piedra, el árbol, la roca o la nube no pueden ocultar su ser, mientras que la persona puede «callar».

A la "persona»-como veremos ampliamente al tratar este concepto scheleriano en la Tercera Parte - no se puede llegar mediante los actos espontáneos del conocimiento metafísico, sino en virtud del «acto religioso" en cuanto correlato esencial de la revelación divina que se funda en último término en su amor.

Apuntemos, finalmente, que la revelación, para $M$. Scheler es un acto libre de la persona divina que presupone ciertas condiciones por parte del hombre, logrando así su sentido la afirmación scheleriana de que la revelación divina, hasta cierto sentido, depende del hombre mismo. Piénsese si no en la tragedia existente entre el sol y el ciego, a la que esporádicamente alude $\mathrm{M}$. Scheler.

\section{El concepto de participación}

La «participación» es uno de los conceptos angulares de M. Scheler, de forma que Przywara no duda en afirmar que todo su pensamiento puede resumirse en un complejo "sistema de participación»" ${ }^{119}$.

Aunque nuestra intención, en este momento, se cifra en hacer más comprensible el pensamiento scheleriano sobre las diferentes formas de automanifestación de Dios apoyándonos én su concepto de participación, a fin de que nuestra mirada no sea parcial queremos asomarnos a la compleja problemática filosófica implicada en el concepto de participación subrayando tres momentos concretos:

\section{a) Platón}

Hay que apresurarse a eliminar radicalmente la interpretación del concep-

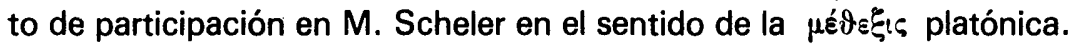

Es cierto que podemos constatar ciertas cadencias platónicas en el concepto de $M$. Scheler, sin embargo existen tales diferencias que hacen controvertible y problemática toda comparación.

117. Ew. M. 146.

118. Ew. M. 331ss.

119. Religionsbegründung. M. Scheler-J. H. Newman, Freiburg: Herder 1923, 2. 


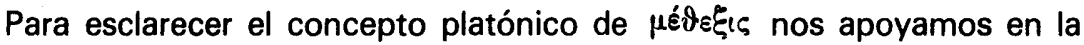
autoridad de N. Hartmann ${ }^{120}$ y de D. Ross ${ }^{121}$ sin pretensiones ulteriores.

N. Hartmann resume asi el pensamiento sobre el concepto de participación en Platón: "Se tendría que tratar propiamente de una participación dual: la participación de las cosas sensibles en las ideas y la participación del alma en las ideas. Esta última ni la tratan ni se hacen problema de ella tanto Platón como aquellos que critican su teoría» ${ }^{122}$.

La participación en Platón se circunscribe, por tanto, al área relacional de las cosas sensibles y las ideas. El problema gnoseológico de la experiencia de las esencias igual que la cuestión epistemológica sobre la relación sujetoobjeto es totalmente ajena a Platón.

Ahora bien, en cuanto a la relación existente entre las cosas sensibles y las ideas, D. Ross nos presenta una amplia panorámica de los múltiples conceptos en virtud de los que se esfuerza Platón por determinarla.

D. Ross subraya que Platón, por una parte, se aproxima a la concepción de una inmanencia de las ideas en las cosas sensibles, mientras que por otra parece inclinarse por su trascendencia. Incluso en los últimos Diálogos - afirma D. Ross - aunque Platón ponga de relieve la trascendencia de las ideas, apunta - como en el Parménides - una cierta inmanencia de las mismas ${ }^{123}$.

\section{b) La filosofia medieval}

La filosofía escolástica - lo hemos visto al reseñar anteriormente el augustinismo medieval - presenta una forma estático-ontológica de la participación. La creatura participa del creador «per modum assimilationis», abriendo asi un hiato dentro de la esfera del ser entre el "esse per essentiam» y el "esse per participationem», que es exponente del pensamiento analógico $y$ del concepto de "ejemplaridad», fórmula esta por la que se cree evadir el peligro tanto de una filosofía de la identidad como de un dualismo metafísico.

Ya conocemos el final de ambas'concepciones de «participación»: la platónica cae ante las crítiças de Aristóteles; la escolástica-medieval se viene a bajo en cuanto la filosofía moderna interpreta el mundo como obra del hombre y los objetos cognoscitivos como producto de la espontaneidad de la conciencia. 1935.

120. Das Problem des Apriorismus in der platonischen Philosophie, Berlin: De Gruyter

121. Platos Theory of Ideas, 2nd. Ed., Oxford: University Press 1951.

122. I.c., 246.

123. I.c., 230ss. 
c) Participación en M. Scheler como concepto ontológico

1

Aunque el concepto scheleriano de participación, fija de una manera ontológica el saber y el conocimiento, el carácter dinámico de su metafísica final amenaza con destruir el esquema ontológico-estático de participación. Lo que aparece como inmutable y fijo en el orden de las formas del saber, se presenta en su metafísica final, en cierto sentido, como producto de una evolución en la que se encuentra en principio un "saber ek-stático»: "No hay nada más erróneo que... el definir el saber mismo... como un contenido de conciencia. Se aclara esto solamente cuando oponemos a esta especial clase de saber y de ser-sabido, que llamamos ser-consciente, otra clase de saber, que le antecede y que no encierra de ninguna manera la clase del ser-consciente. Queremos designar este saber como saber ek-stático»" ${ }^{124}$.

Pero prescindiendo de todas las modificaciones, ampliaciones, precisiones con las que $M$. Scheler intenta presentar lo más adecuadamente su pensamiento, repite con insistencia que el «saber es una relación óntica» ${ }^{125} \mathrm{y}$ que «ha de estar determinado por conceptos puramente ontológicos», al consistir en «la participación de un ser en el ser-asi de otro sin que experimente el ser-así ninguna variación» ${ }^{126}$.

Al ser el saber "participación óntica», la experiencia de la realidad - como ya hemos visto - es subordinada a aquella parte del hombre que es contraria al espíritu: el impulso (Drang) en su vivencia de resistencia.

Esta división intrínseca del hombre es presupuesto esencial de la teoría de la participación - como aparece claramente en su filosofía final-con la que explica M. Scheler el conocimiento y el saber, atribuyendo el conocimiento del ser-así a la esencia espiritual (Geist) y la vivencia del ser-real al «impulso» (Drang).

M. Scheler que distingue varias formas del saber, asigna al concepto de participación la tarea de servir de mediación entre el sujeto y el objeto para lograr la identificación con el ser-así: «Todo conocimiento se realiza en la rigurosa correspondencia e identificación recíproca entre imagen y significación, pero apuntando al ser-así del ser de la cosa misma, ser-así uno en sí mismo y ónticamente indiviso e indivisible»" ${ }^{127}$.

En conexión con las diferentes formas del saber se desmembra el ser-así en distintos modos que $M$. Scheler designa con los términos ser-así accidental y esencial:

124. I-R. 260.

125. W. Ges. 203.

126. Ibd.

127. I-R. 267. 
Al «saber de Dominio» le corresponde el ser-así accidental

Al «saber de formación» la esencia

Al «saber de salvación» el ser del Fundamento supremo de las cosas.

II

Pero M. Scheler conoce además una "óntica del Absoluto» que se manifiesta en ulas distintas maneras y formas de participación de nuestro ser humano en el ser de Dios, dentro de las que el conocimiento y el saber del ser del Fundamento supremo de las cosas es sólo una clase»" ${ }^{28}$.

En la Tercera Parte, al tratar del concepto «teomórfico» del hombre ${ }^{129}$, de la «identidad parcial» de su esencia con la esencia de Dios ${ }^{130}$, de "velle» y del "amare in Deo» ${ }^{131}$, de la inserción del hombre en el proceso teogónico como «co-autor» y "co-realizador» ${ }^{132}$ dedicaremos nuestro estudio a un análisis detenido de estas formas de participación del ser humano en el ser de Dios, conformándonos ahora como hemos dicho, con una breve alusión que sirva para comprender mejor las diferentes formas de autor-manifestación de Dios.

Por una parte Dios se refleja como ser absoluto en todo ser limitado:

"La inmanentia Dei in mundo» pertenece a la esencia de Dios. Dios está en toda cosa existente en cuanto «es». Toda existencia participa en su ser y sólo por esta participación hay un mundo» ${ }^{133}$.

En esta obra precisamente rechaza $M$. Scheler todo matiz panteísta «pues el mundo es por su realidad distinto de Dios y sólo porque Dios es espíritu infinito puede estar en todo" ${ }^{134}$. Sin embargo, germinalmente, se encuentra aquí la afirmación categórica del Puesto del hombre en el cosmos. "La conciencia del mundo, la conciencia de si mismo y la conciencia de Dios forman una indestructible unidad estructural») ${ }^{135}$.

Precisamente de esta participación del ente finito en Dios brota la «relación simbólica e intuitiva» con la que nos tropezaremos al hablar de las cosas del cosmos como "campo de expresión de Dios». Es cierto que si buscamos en el M. Scheler de este tiempo la esencia de esta participación en una fórmula concreta, sólo descubrimos expresiones metafóricas ${ }^{136}$.

Por otra parte al ser la persona de Dios unidad arquitectónica de actos - como veremos al estudiar el concepto scheleriano de persona - la participación del hombre en él ha de consistir en la co-ejecución de sus mismos ac-

128. Ew. M. 285.

129. Eth. 293.

130. Sym. 141.

131. Ew. M. 304, 220.

132. Phil. W. 15.

133. Ew. M. 189.

134. Ibd.

135. Stell. 83.

136. Cfr. Ew. M. 162-163. 
tos: "La participación del hombre en un ser que no es ser-objeto, sino ser de acto, sólo puede darse en la co-ejecución de este acto, no siendo por tanto conocimiento del objeto" ${ }^{137}$.

Tenemos además que el valor de lo "Santo" es el primer y supremo valor ${ }^{138} y$, según los axiomas del valor, aquél que no se puede deducir de los demás y que "fundamenta a todos» ${ }^{139}$, aquél que es indivisible por excelencia ${ }^{140}$ y comunicable de una manera indivisible ${ }^{141}$.

Finalmente el hombre, como persona espiritual, participa en el «reir.o de Dios» ${ }^{142}$ en virtud del vínculo del amor ${ }^{143}$.

Podemos decir, pues, de una manera general, que el concepto de participación en el ser de Dios inunda, en la cosmovisión scheleriana, toda la creación, erigiéndose en uno de los conceptos angulares.

\section{REVELACIÓN NATURAL}

En los escritos schelerianos de 1913 a 1921, tiene una gran importancia la revelación para la comprensión de las realidades del mundo, del alma espiritual y sobre todo del hombre.

Se parece vislumbrar a Dios en el trasfondo de todo. Esto se transforma por cierto, en su última época, en una deificación de las cosas y, sobre todo del hombre, de modo que lo que en principio era coeficiente histórico augustiniano converge en un panenteísmo o panteísmo manifiesto.

M. Scheler toma su punto de partida de la cosmovisión augustiniana: «Desde el primer átomo, desde la parte más insignificante hasta Dios, este reino es un único reino» ${ }^{144}$. El mundo representa un "cosmos», en sentido auténtico, dentro del que todo miembro singular del macro-cosmos, es en sí mismo un micro-cosmos; cada miembro de este todo macrocósmico, participa de Dios y «es» mediante esta participación: «Dios está en toda cosa existente, en cuanto es, toda existencia participa de su ser y sólo por esta participación hay un mundo» ${ }^{145}$.

En cuanto que todo ser está en Dios como Ser y Valor absoluto, todo ser y valor es una automanifestación de Dios. Toda aprehensión del ser y todo conocimiento del valor es "saber sobre Dios», mediante Dios mismo, y ya hemos visto que el saber en $M$. Scheler, es una participación del ser sabido. Sin

137. Ew. M. 71-72.

138. Eth. 125.

139. Eth. 112.

140. Eth. 110.

141. Eth. 103.

142. U.d.W. 97.

143. Eth. 293.

144. Nachl. 357.

145. Ew. M. 189. 
embargo, esta participación de toda creatura de Dios no significa una «immanentia mundi» en Dios, sino una «immanentia Dei in mundo».

Del hecho fundamental de la inmanencia de Dios en el mundo por la participación de las cosas en Él, se da una triple consecuencia:

a) Toda realidad del mundo es una revelación natural de Dios;

b) Esta revelación natural de Dios, se basa en una relación simbólica de la naturaleza;

c) La relación existente en la revelación natural, es óntica y de carácter simbólico-intuitivo.

Pasemos a la explicación de cada uno.

a) Toda realidad del mundo es una revelación natural (Werkoffenbarung) de Dios

M. Scheler, igual que S. Agustín, considera la creación «in lumine Dei». La creatura es «huella», "dedo», "expresión» de Dios. Toda estructura natural es obra de Dios creador, invisible por ser espíritu, es un trampolín que eleva hasta Dios, una huella de sus pies, una manifestación de su magnificencia. La naturaleza, es pues, un "campo de expresión» de Dios: «así como en un rostro humano se expresa la alegría o la tristeza, en la sonrisa o en las lágrimas» así se transparenta lo Divino en las cosas naturales como upotente y activol) ${ }^{146}$.

Lo Divino no se encuentra, pues, al final de una dedución sino al principio de toda consideración. Por su revelación es el «siempre-presente». Las cosas naturales aparecen sobre el horizonte divino y se recortan en su individualidad sobre él.

b) La revelación natural de Dios, se basa en una relación simbólica de la naturaleza

La naturaleza no es un signo externo y convencional que significa a Dios: es una imagen interna, un símbolo de Dios. $Y$ ya sabemos la función que ha de desempeñar siempre al símbolo: "Le Symbole identifie, assimile, unifie des plans hétérogènes et des réalités en apparence irréductibles》) ${ }^{147}$

Este simbolismo de las realidades naturales, es, por cierto, distinto de $M$. Scheler, que en la corriente augustiniana. Agustín, Descartes, y Malebranche afirman que no se puede aprehender una verdad finita, la bondad de un hombre concreto, sin aprehender simultáneamente la idea de una verdad universal, y una bondad suprema, la misma idea de Dios: «de igual manera que no se puede concebir como tal una línea recta limitada, sin compararla con una completamente infinita y sin considerarla como una parte de la misma» ${ }^{148}$.

146. Ew. M. 162.

147. M. Eliade, Traité d'histoire des religions, Paris: Gallimard 1949, 388.

148. Eth. 176 
En M. Scheler no se da un simbolismo inmediato, sino mediato que no es aprehensible por cierto por medio de una deducción causal, sino solamente por el acto religioso el hombre. Toda la creación en su función indicadora de Dios está en adviento, en espera. Es el hombre con su acto religioso quien consuma esta función de la creatura interpretando su lenguaje cósmico: "La evidencia - la iluminación de la esencia en la que se representa en el sentido más estricto como auto-dada - , adquiere ahora el carácter de una revelación natural de Dios por la que Él adoctrina el espíritu cognoscente del hombre sobre la esencia y sentido de su obra creadora» ${ }^{149}$.

c) La relación existente en la revelación natural, es óntica y de carácter simbólico-intuitivo

No necesitamos fundamentar este punto que es una consecuencia de la participación de las realidades naturales en Dios y del hecho de que las cosas son símbolo de Dios interno y no solamente externo. M. Scheler rechaza expresamente toda interpretación panteísta igual que la lógica y la causal.

Se mueve repetidas veces, al margen del panteísmo, aunque en su primera época le rechaza consciente. Aquí tampoco deja pasar la oportunidad en vano: "Una concepción de la relación muy tosca, que juega con analogías sensibles, es la concepción panteísta» ${ }^{150}$.

La participación de las realidades naturales en Dios, arbotante de la relación simbólica de la creación se tiene que distinguir, pues rigurosamente de un panteísmo acosmista, ya que no parte de la esencia de las cosas sino de la plenitud infinita de Dios.

Igualmente rechaza la interpretación lógica y causal de la relación existente en la revelación natural:

"La relación que se encuentra en el «revelarse» es una relación que pertenece a la clase de relaciones simbólicas e intuitivas: del ser signo (objetivo) de algo, del indicar de un objeto a otro... del anunciarse, comunicarse, expresarse.

Aquí se trata, no de conceptos de relación como de operaciones mentales de inferencia o interpretativa... El punto de partida de la relación simbólica del mostrarse, no es tampoco un contenido del espíritu humano, así como en la palabra hablada se muestra la significación, sino que es el objeto del ente relativo mismo, en el que se muestra el portador del ser absoluto, en el que "se abre». Se trata, pues, de una relación de ser, y sin embargo no lógica, como igualdad, semejanza, o causal, sino una relación simbólica e intuitiva»" ${ }^{151}$.

149. Ew. M. 298.

150. Ew. M. 191.

151. Ew. M. 161. 


\section{EPIFANIAA DE DIOS EN EL HOMBRE}

Aunque de este tema nos ocuparemos en la Tercera parte de nuestro trabajo anticipamos aquí algunas ideas.

La transparencia de Dios en las realidades naturales aparece de una manera similar en el alma espiritual que está «enraizada en Dios» ${ }^{152}$, al representar «por su esencia y quiddidad y por el contenido del destino que se sigue de ella, el contenido mismo de la idea de Dios y no en modo alguno una mera «imagen» de ella» ${ }^{153}$.

Por lo que toca al hombre en su sentido esencial, es en principio para $\mathbf{M}$. Scheler, sólo aprehensible «bajo la luz» de la idea de Dios ${ }^{154}$. La antropología scheleriana, conoce un primer estadio que está marcado de un «supernaturalismo" palmario: "Una cosa que empieza a ir más allá de sí misma y a buscar a Dios es ya hombre, parezca lo que parezca» ${ }^{155}$.

El hombre natural se diferencia del animal, solamente de una manera gradual. La diferencia esencial entre ambos está constituida por el hecho de que el hombre es «Hijo de Dios» ${ }^{156}$.

El hombre es en su ser «intención», «gesto de la trascendencia» ${ }^{157}$, es la «dirección» del universo hacia Dios» ${ }^{158}$. Es un «estado intermedio» ${ }^{159}$, es un "puente» entre dos órdenes de ser y de esencias en los que está igualmente enraízados «el animal y Dios» ${ }^{160}$. El hombre es el «aparecer de Dios» en la corriente de la vida y un eterno "más allá de la vida sobre sí misma» ${ }^{161}$. Finalmente diríamos que se da una auténtica antropogénesis, es decir, el hombre es precisamente hombre, por la irrupción de Dios en él: "así como la ventana de una casa sólo resalta de la serie de ventanas restantes, porque un hombre se asoma a ella, el objeto finito, sólo llega a ser "especial» y "santo», porque simboliza al "Ser absoluto» ${ }^{162}$, porque se asoma Dios a través de él.

Ya hemos encontrado este pensamiento, repetidas veces, como proveniente de Agustín. Por lo demás es frecuente en M. Scheler: «Si valoramos de ese modo al "hombre» suponemos en realidad, valores que son independientes de los citados, a saber: los valores de lo santo y los valores espirituales. Quiere decir, que el hombre es «el ser superior a los otros», en tanto, y sólo en

152. Ew. M. 195.

153. Symp., 137.

154. Eth. 293.

155. Ew. M. 189.

156. U.d.W. 194

157. U.d.W. 186.

158. Ibd.

159. Ibd.

160. Nachl. 69.

161. U.d.W. 186

162. Ew. M. 160. 
tanto, que es depositario de actos independientes de su organización biológica y en cuanto que ve y realiza los valores que corresponden a esos actos» ${ }^{163}$.

Al ser lo Divino «ser-acto» ha de consumar el hombre esta participación que tiene en Dios, por medio de la co-ejecución de sus actos. M. Scheler llega a afirmar, incluso, que el acto del "velle», "amare in Deo», es realmente distinto de Dios, pero idéntico en cuanto a su contenido ${ }^{164}$.

En su primer período, rechaza, como hemos visto, el panteísmo. Sin embargo, en su última época (1923-1928) coloca $M$. Scheler en el hombre, todo el peso ontológico en la ayuda que ha de prestar a Dios en el proceso de su desarrollo en la historia. En la Parte tercera de nuestro estudio, hablaremos detenidamente, acerca de este punto. Contentémonos, ahora, solamente con su insinuación.

Esta concepción antropológica descrita de una manera general, sobre la idea de la epifanía de Dios en el hombre hace visible el "sin-sentido" de todo antropomorfismo con respecto a la idea de Dios: «esto es tan falso que la única idea del hombre llena de sentido es la de un total y absoluto teomorfismo» ${ }^{165}$.

\section{REVELACIÓN POSITIVA}

Las cosas naturales, como campo de expresión de Dios, el alma espiritual, el hombre - todos son portadores de la revelación divina pero de una manera distinta entre sí.

La revelación natural se basa, en un sentido estricto, en las cosas naturales. El hombre como realidad natural, es una revelación natural "cosificada» de Dios, pero como ser espirituai, forma un eslabón que une la revelación natural con la positiva.

Las realidades naturales expresan, señalan, apuntan a Dios y son un trampolín que nos eleva a Ėl. Pero la revelación natural de Dios está en ellas en adviento, en espera, y en la consumación de esta función expresiva, llegan las cosas naturales a la realización de su último sentido.

Solamente el hombre, puede interpretar esta revelación natural en las cosas. El hombre es capaz de entender el lenguaje cósmico, si bien es verdad sólo parcialmente ${ }^{166}$. Al ser interpretado por el hombre, este lenguaje mudo de las cosas, al descifrar su simbolismo, se dá lo que designa M. Scheler, en dependencia de Agustín «redención de las cosas» en su apuntar a Dios ${ }^{167}$.

\footnotetext{
163. Eth. 293.

164. Eth. 220.

165. Ibd.

166. Ew. M. 269.

167. Ew. M. 299.
} 
De todo esto, brota el que la auto-manifestación de Dios, tenga su destino último en el hombre. La revelación de Dios en el hombre es, pues, capital en el.sistema religioso de $\mathrm{M}$. Scheler.

Este hecho explica quizá el que sea designado su sistema filosófico «sistema de revelación positiva». Przywara, llega a afirmar: "tenemos, pues, que preguntarnos: ¿no es la consecuencia propia de su sistema la revelación positiva?» ${ }^{168}$. M. Dupuy es de la misma opinión: «Incontestablement, le point de vue du Formalisme s'est élargi, mais le rôle de la révélation positive est loin d'être négligé»" 169 .

Reconocemos que tanto Przwara como Dupuy aportan ciertas afirmaciones de $M$. Scheler que a primera vista, pueden apoyar su interpretación: «La realidad de Dios asienta única y exclusivamente en una posible revelación positiva de Dios, que tiene lugar en una persona concreta» ${ }^{170}$.

Por otra parte, encontramos en De lo Eterno en el hombre estas palabras: «con la aceptación de la personalidad de Dios, está determinada la manera y la forma en la que ha de venir dada la comunicación (revelación) de Dios al hombre: por medio de personas humanas ${ }^{171}$.

A pesar de esta interpretación, creemos que hay que admitir en general que el proceso del pensamiento de $M$. Scheler, deja muchos puntos, sin apenas matizarlos. Este es el motivo porque nosotros hemos de profundizar en el sentido de esta "comunicación» "por medio de personas humanas».

Para interpretar la doctrina de la manera más genuina, tomamos nuestro punto de partida del pensamiento fundamental de que el hombre es un estadio intermedio, un punto de convergencia, constituyendo el destino último de la revelación divina. Solamente puede el hombre escuchar, e interpretar el lenguaje cósmico y por otra parte, él escucha también la palabra directa de Dios.

Esto presupuesto, podemos librar al pensamiento de M. Scheler, de una posible equivocidad.

M. Scheler distingue, junto a la revelación natural de las obras naturales ${ }^{172}$, otra clase de revelación que se «presenta o anuncia por medio de la palabra y mediante personas» ${ }^{173}$, la revelación positiva. Como ya hemos dicho, presenta esta revelación positiva, "por medio de personas», una doble modalidad: «una que está destinada como tal a la persona total del todo solidario y otra que va destinada a la persona singular». En virtud de esta distinción: «puede toda persona por dos motivos, en principio, distintos, realizar el faith-acto, con respecto a la realidad de la esencia a priori, evidente de Dios.

168. Zu M. Schelers Religionsauffassung, 41.

169. La Philosophie de la Religion chez M. Scheler, 173.

170. Eth. 395.

171. Ew. M. 337.

172. Nachl. 190.

173. Ew. M. 157. 
Por una parte, en cuanto es miembro solidario de la Iglesia, iglesia que por el carácter mediador de su fundador y la revelación de Dios posee el acervo salvífico y universalmente válido de la revelación y le ofrece a todo miembro para que le crea. Por otra parte, en cuanto que la misma persona recibió la auto-manifestación de Dios, por medio de su propia experiencia religiosa» ${ }^{174}$.

Ahora bien, la experiencia religiosa, aunque es inmerecida, no constituye ningún medio extraordinario para el conocimiento de Dios, cosa que incluye la revelación positiva en sentido estricto.

La experiencia religiosa es "la experiencia de Dios que todo hombre puede tener en lo profundo de su personalidad y en el contacto místico del núcleo de su alma espiritual-personal con la divinidad bajo condiciones dispositivas concretas e internas» ${ }^{175}$.

Por otra parte, acentúa M. Scheler que sería una interpretación errónea, confudir la revelación de Dios en el acto de la experiencia religiosa, con la «experiencia» que las teologías dogmáticas designan como «revelación positiva» ${ }^{176}$.

Aquella, es "un tercer principio de conocimiento" ${ }^{177}$, que corresponde a todo hombre; es el eslabón que une las dos clases fundamentales de revelación: natural-positiva. Por una parte, interpreta el lenguaje cósmico, y redime a las cosas en su función indicadora de Dios, por otra, está próxima a la revelación positiva en el sentido tradicional, ya que en ella se manifiesta Dios como persona:

«el núcleo de nuestra opinión es, pues, que si se dan estas dos condiciones, la negativa y la positiva, y si la persona en cuanto tal, mediante una total concentración está en posesión de su propia esencia, si no se deja mover por el alma vital, ni se siente movida por ella, adquiere, y adquiere de una manera necesaria, en una unidad vivencial indestructible e indivisible, en un mismo momento, de una manera indefectible, su propia sustancia en Dios y Dios en ella misma, como realidad y como persona" ${ }^{178}$.

M. Scheler intenta, pues, unir por medio de la auto-manifestación de Dios en la experiencia religiosa, la doctrina tradicional de revelación natural y positiva.

La revelación en la persona singular, está constituida primordialmente por un "encuentro», que consiste en "un contacto con Dios en el amor divino» ${ }^{179}$.

No queremos entrar en más disquisiciones sobre este punto. Nos es suficiente con constatar que en $\mathrm{M}$ Scheler se distingue la revelación de Dios en la

174. Nachl. 232.
175. Ew. M. 21.
176. Ibd.
177. Ew. M. 21.
178. Ew. M. 23.
179. Ew. M. 82. 
persona singular de la revelación positiva, en sentido tradicional: «un Dios que permite que los hombres de un grupo tengan más "aptitud» para experimentarle que otros... puede ser todo menos Dios» ${ }^{180}$. Al mismo tiempo es esta clase de revelación, totalmente distinta de la revelación natural en las cosas, pues en ella se manifiesta Dios como persona ${ }^{181}$, miestras el correlato de la revelación natural (Werkoffenbarung) en las cosas es «la pura cualidad de lo Divino o de lo Santo que se nos ofrece en una plenitud infinita de ser» ${ }^{182}$.

Esta es, según nuestra opinión, la exposición objetiva del pensamiento de M. Scheler. Claro, que no hay que confundir la "quaestio facti» con la «quaestio iuris», cosa que parece darse en $M$. Scheler: una cosa es el hecho de que se dé, y otra, muy distinta, el que le pertenezca, esencialmente, al hombre. En $M$. Scheler, aparece una volatilización de lo diferencial del orden natural y sobrenatural. En la confusión de elementos pertenecientes a distintos órdenes radica el hecho de que cegado de grandezas, converja su pensamiento en la cosmovisión final.

180. Ew. M. 24

181. Ew. M. 24-25.

182. Eth. 298. 


\section{CAPITULO CUARTO}

\section{EIDOLOGIAA DEL OBJETO RELIGIOSO}

\section{ÓNTICA ESENCIAL DE LO DIVINO}

La fenomenología de la religión abarca en M. Scheler, como hemos visto, por una parte, la fenomenología del "objeto religioso» - en su «consistencia» (Bestand) y en su "contenido" (Gehalt) - y sus diferentes formas de autorrevelación.

Al dársenos el ser, en todos los órdenes del conocer, con anterioridad a su conocimiento, ha de ser lo divino un dato originario de nuestra conciencia; el primer pilar por tanto de la fenomenología de la religión está constituido por la fenomenología del objeto religioso, llamada también por $\mathrm{M}$. Scheler «óntica esencial de lo divino".

Ahora bien, y dentro del campo de la fenomenología, al determinar la quiddidad de un objeto, en cierto sentido, la naturaleza del acto en que es aprehendido $y$ al formar objeto $y$ acto una estructura indivisible, «una totalidad originariamente cerrada en sí misma» ${ }^{183}$, la fenomenología del objeto religioso implica necesariamente la fenomenología del acto religioso en el que "aparece» y en que «se manifiesta».

Empezamos por la "óntica esencial de lo divino», volviendo de nuevo, en una forma más explícita, sobre la fenomenología del objeto religioso.

M. Scheler agrupa las determinaciones originarias de lo divino, que se manifiesta en el acto religioso, como correlato esencial, en «las determinaciones más formales de un ser $y$ de un objeto de la esencia de lo divino" ${ }^{184} \mathrm{y}$ los "atributos positivos-naturales», "a diferencia de aquéllos que llamamos formales y de aquéllos que sólo se deben a la automanifestación positiva de Dios en las personas santas» ${ }^{185}$.

Las determinaciones formales describen el mínimo necesario pero suficiente para que su objeto sea precisamente «objeto religioso»: "Son las úni-

183. Ew. M. 169

184. Ew. M. 169

185. Ew. M. 176. 
cas que constituyen y configuran necesariamente la esfera objetiva de una actitud consciencial religiosa» ${ }^{186}$.

En contraposición a las determinaciones formales, aunque propiamente sea una "coincidentia oppositorum», las determinaciones positivo-naturales son designadas por $M$. Scheler con distintos términos: «atributos ulteriores» ${ }^{187}$, «supraformales» ${ }^{188}$, «determinaciones materiales de los atributos naturales de Dios» ${ }^{189}$.

Desde un punto de vista general M. Scheler diferencia las «determinaciones formales» de las «materiales» de la siguiente forma: «Para las determinaciones formales es, pues, válido el principio de que conocemos siempre la existencia y la esencia del mundo 'a la luz' de algo divino, cuya concepción subjetiva es tanto histórica como sociológicamente variable. Para las determinaciones materiales de los atributos naturales de Dios, al contrario, es cierto que sólo los conocemos a la luz de nuestra visión esencial de la constitución interna del mundo, no conociendo aquí el mundo a la luz de Dios, sino a Dios en el espejo del mundo; sin perjuicio de la variabilidad cualitativa de la concepción formal de lo divino, la variabilidad de la concepción de los atributos positivos de Dios no es sólo cuantitativa sino cualitativamente superior»" ${ }^{190}$.

Bajo los atributos formales coloca M. Scheler «las tres determinaciones: ens a se, poder $y$ eficacia absolutos, $y$ santidad" ${ }^{191}$ y bajo los materiales «espíritu, razón voluntad, amor, misericordia, omnisciencia, bondad absoluta, etc. ${ }^{192}$.

\section{DETERMINACIONES FORMALES DE LO DIVINO}

\section{a) Determinaciones óntico-esenciales}

No procede M. Scheler, por deducciones silogísticas, sino que apoyándose en el acto de la experiencia religiosa afirma:

«En virtud de los actos religiosos naturales ve, piensa y siente el hombre, primordialmente, en todo y por todo, algo que le es dado como existencia y esencial, algo que se le abre (se le «revela») como un ser que posee al menos, dos determinaciones esenciales: es un ser Absoluto y Santo" ${ }^{193}$.

La determinación de la excelencia absoluta del Ser Supremo, ante el que

\footnotetext{
186. Ew. M. 169

187. Ew. M. 171

188. EW. M. 172

189. Ew. M. 176, nota 1.

190. Ibd.

191. Ew. M. 169.

192. EW. M. 172

193. Ew. M. 159.
} 
el hombre, igual que toda creatura, se siente dependiente por naturaleza, no es deducida por medio de la causalidad, es más bien, originaria en el acto de la experiencia religiosa; no se llega a ella mediante la capacidad discursiva de la razón espontánea, sino que se nos da mediata o inmediatamente, se nos manifiesta en el mundo interior o exterior: podriamos hablar de una «intuitio per signum».

En el ser absoluto, son inseparables la plenitud ontológica y la causalidad universal. La plenitud ontológica - que se refleja en la vivencia de la nada existencial humana-- es la determinación fundamental de lo Divino, diríamos, "ad intra», la causalidad es "ad extra».

Estas dos dimensiones de lo Divino despiertan en el hombre el sentimiento de dependencia. Aquí está M. Scheler en completo acuerdo con Rudolf Otto, que en su libro Lo Santo, censura la postura de Schleiermacher: "A su juicio, el sentimiento religioso, sería un sentimiento de mí mismo, el sentimiento de una peculiar condición mía: de mi dependencia. $Y$ sólo por conclusión lógica, refiriendo mi estado a una causa exterior a mí, es, según Schleiermacher, como yo encuentro lo Divino. Pero el sentimiento de creatura, es un momento concomitante, un efecto subjetivo, por así decirlo, la sombra de otro sentimiento, que de una manera inmediata se refiera a un objeto fuera de mí». ${ }^{194}$.

Schleiermacher es víctima de una confusión: toma como punto de partida lo que es solamente consecuencia. El ser absoluto no es «imaginado», «inferido" por la conciencia de una dependencia absoluta, sino al contrario: la intuición del ens a se polariza en la vivencia de la nihilidad de la creatura. En la relación entre el ens a se y el contingente distingue $M$. Scheler lo vivencial de lo deducido. Por otra parte, en las cosas naturales no existe una relación lógica sino óntica. De aquí la trasparencia de Dios en las cosas como ser supremo.

\section{b) Determinación axiológico-esencial}

Al acercarnos a la determinación axiológico-esencial de lo divino como "santo», hemos de referirnos, en principio y a grandes rasgos, a la concepción axiológica general de $\mathrm{M}$. Scheler.

Los valores son para él "fenómenos» autónomos, "cualidades materiales», "objetos ideales», "estructuras intencionales»; tienen su propia esencia y se manifiestan en el «sentir», no teniendo éste nada en común con los meros «sentimientos». Los valores son correlatos noemáticos del "preferir» y «postergar» y del amor y del odio.

194. Das Heilige, 10. 
El pertenecer un «ser autónomo» a los valores es exponente indeterminado de la oposición a estos hechos fenomenológicos al «ser» en cuanto tal. Por este motivo no puede determinar M. Scheler el ser del valor ${ }^{195}$.

Certeramente apunta Deininger que la circunstancia de que tanto los "hechos fenomenológicos» como el "ser» en cuanto tal "sean», no puede tener en $M$. Scheler un sentido positivo, sino una significación eminentemente negativa: ambos «no-son-nada». $M$. Scheler no puede asomarse a la «plenitud y totalidad» del ser recurriendo a la "experiencia de la nada»:

«Quien, por así decirlo, no se ha asomado al abismo de la nada no podrá comprender nunca la positividad absoluta del contenido de la intuición de que 'es algo mejor que nada'»' ${ }^{196}$.

M. Scheler separa inexorablemente el ser del valor y el valor del ser. Ningún valor puede reducirse al ser o inferirse de él. Los valores constituyen una región apriórica de objetividades materiales que tienen como correlatos noéticos esenciales los actos emocionales del preferir y postergar, de amor y de odio.

No es nuestra intención - por cuanto superaría los límites del objetivo de nuestro trabajo-- exponer los resultados de la actitud crítica ante la concepción scheleriana de los valores. En este sentido, remitimos a M. Müller ${ }^{197}$ cuya crítica detallada creemos decisiva.

Volviendo a la concepción general de los valores en $M$. Scheler, éstos constituyen un reino apriórico jerárquicamente estructurado, destacando $M$. Scheler cinco propiedades en virtud de las cuales están reguladas sus correlaciones esenciales: «Duración» ${ }^{198}$, «indivisibilidad» ${ }^{199}$, "fundamentación» ${ }^{200}$, "profundidad de satisfacción» ${ }^{201}$ y «carácter absoluto» ${ }^{202}$.

Este orden jerárquico existente entre las «modalidades axiológicas», entre "los sistemas cualitativos de valores materiales» es designado por $\mathrm{M}$. Scheler como "la realización apriórica más importante y rigurosa» ${ }^{203}$.

Según este orden jerárquico apriórico todos los valores tienen su última justificación en el valor supremo de lo "santo»: "Logramos la idea de Dios como idea personal de valor al concebir totalmente completo el orden jerárquico de los valores... y realizado al mismo tiempo por la plenitud infinita de la cuali-

195. Cfr. D. Deininger, Die Theorie der Werterfahrung und der Begriff der Teilhabe in der Philosophie M. Schelers, 47ss.

196. Ew. M. 93.

197. Über Grundbegriffe philosophischer Wertlehre, Logische Studien über Werbewusst sein und Wertgegenständlichkeit, Freiburg: Waibel 1932.

198. Eth. 110.

199. Ibd.

200. Eth. 112.

201. Eth. 113.

202. Eth. 114

203. Eth. 112 
dad material-axiológica, aunque es verdad que no se agota con esto la divinidad» 204

Bajo la expresión de lo "santo» no entiende M. Scheler «una clase de objetos especial y definible, sino (primordialmente) todo objeto de la «esfera del Absoluto" ${ }^{205}$. Por otra parte, al ser los valores de las personas superiores a los valores de las cosas ${ }^{206}$ lo "santo", en el que tienen todos los valores su fundamento último, ha de ser persona, pero no una persona infinita sino una persona de valor infinito ${ }^{207}$.

II

En El formalismo en la ética y la ética material de los valores aparece la vertiente exclusivamente axiológica de lo divino como supremo valor, como la persona de valor más perfecta, como lo infinitamente santo, cuyo núcleo más profundo es el amor.

En su última página, sin embargo ${ }^{208}$, promete $M$. Scheler una ampliación (Ergänzung) en la determinación de lo divino. Esta promesa es cumplida en su obra De lo Eterno en el hombre, donde presenta la dimensión óntica junto con la axiológica.

Hemos de observar que la irreductibilidad scheleriana de valor-ser, tiene un significado especial sobre el horizonte divino: ha de tratarse sólo de una "distinctio rationis». En De lo Eterno en el hombre, se establece una distinción entre Dios, como objeto inmanente (ens intentionale) y la realidad transsubjetiva (ens reale), «en el primer caso existe una bifurcación en dos objetos: el ente intencional del conocimiento del ser (como ens a se) y el término intencional de la aprehensión axiológica (Summum Bonum), mientras Ėl, como ser real, es una misma cosa» ${ }^{209}$.

M. Scheler reduce la doctrina de «dos entes intencionales» a «intenciones primeras» y en último término a urelación de prevalencia». Según esto, hablaría El formalismo en la ética y la ética material de los valores de un VALOR, que es al mismo tiempo ser y el De lo Eterno en el hombre de un SER que es simultáneamente valor.

La determinación esencial axiológica de lo Divino, es de capital importancia en M. Scheler, pues, uel momento de valor no constituye un predicado de la idea ya dada de Dios, sino su fondo nuclear» ${ }^{210}$.

204. Nachl. 181, nota

205. Eth. 125.

206. Eth. 117

207. Eth. 113.

208. Eth. 580 .

209. E. Przywara, Zu M. Schelers Reïgionsauffassung, 26

210. Eth. 297. 
Además, tenemos que el valor, está antes que el ser, y el conocimiento del valor, antes que el del ser: "Todo comportamiento primario respecto al mundo, no sólo exterior, sino también respecto al mundo interior, y no sólo para con los demás, sino también para con nuestro propio yo, no es simplemente un comportamiento "representativo», sino que es siempre, y según lo anteriormente aducido, de un modo primario una conducta emocional $y$ aprehensora de valores»" ${ }^{211}$.

Esta actitud fundamental, tiene su aplicación también en el ámbito de lo Religioso, donde «el percibir sentimental» (el Fühlen-von), que es correlato subjetivo de la determinación axiológica de lo Divino, se encuentra en el mismo umbral del conocimiento de Dios ${ }^{212}$.

Lo Santo, aparece como fenómeno originario, «como perteneciente, ante todo, a lo primariamente dado a la conciencia humana" ${ }^{213}$. Es el Valor Supremo, irreductible al puro complejo, al «totum» cuantitativo de todos los demás valores ${ }^{214}$.

No trata, M. Scheler, de una manera estructurada y profunda la vertiente axiológica de lo Divino; remite a la obra de R. Otto Lo Santo. Intentamos pues completar el pensamiento scheleriano con las «intuiciones» de R. Otto.

Además de otros sentidos, incluye lo Santo un excedente de significación ${ }^{215}$, que R. Otto intenta, ante todo, descubrir por medio de delimitaciones sucesivas, apelando siempre al sentido trascendente de lo Numinoso en el hombre mismo. Lo Numinoso es, precisamente, lo Santo depurado de todo momento moral y racional ${ }^{216}$.

Al intentar percibir en nosotros lo Santo, lo Numinoso, nos encontramos con un "äppriı »", con algo inefable, de lo que sólo podemos hacernos una idea mediante el «reflejo sentimental» que provoca en nosotros ${ }^{217}$. Observemos que, R. Otto, habla siempre de un "Fühlen-von» de carácter intencional y nunca de "Gefühle» que permanecen en la pura subjetividad ${ }^{218}$.

La cristalización de este reflejo sentimental es designada por Otto con el término «ideograma». Los ideogramas de lo Numinoso, no son ningún concepto racional, sino algo similar al concepto, una pura señal indicadora de un momento sentimental de la vivencia religiosa, teniendo presente que esas expresiones no convienen enteramente a lo que queremos significar, sino que solamente aluden a ella ${ }^{219}$.

211. Eth. 206.

212. Ew. M. 350.

213. Ew. M. 159

214. Ew. M. 312.

215. R. Otto, Das Heilige, 6.

216. Ibd.

217. I.c., 8

218. Cfr.: Das Gefüh/ des Uberweltlichen, 327ss.

219. Das Heilige, 66. 
Lo Numinoso, aparece en la "conmoción religiosa» en principio como "Mysterium tremendum» ${ }^{20}$. El sentimiento del "Mysterium tremendum» es un temblor interno y profundo, un silencio del alma que cala hasta sus propios fundamentos. El componente sentimental del «tremori numinoso al ser referido al objeto, de quien procede, descubre una propiedad correlativa en el Nu-

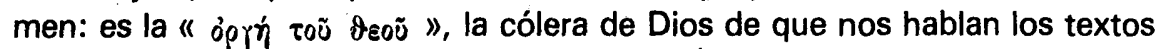
escripturísticos.

La «ira de Dios» «no es, sino lo Tremendo mismo, si bien interpretado mediante una analogía ingenua» ${ }^{221}$.

Lo Tremendo, se puede explicar también por el ideograma de la inaccesibilidad absoluta, pero para expresarlo de una manera completa, hay que agregar al elemento del poder, potencia, omnipotencia.

Aquí elige R. Otto, como nombre-símbolo, la «majestad» 222 y nos encontramos con que lo Tremendo se convierte en «tremenda maiestas».

A este elemento de majestad, de prepotencia absoluta, corresponde, como correlato en el sujeto uaquel sentimiento de creatura que surge al contraste de la potencia superior como sentimiento de la propia ceniza y nada, del anonadamiento y del ser-tierran) ${ }^{223}$.

El momento de lo Tremendo y de la Maiestas encierran en sí un tercero que R. Otto designa como «Energía» ${ }^{224}$. Esta energia del Numen contrapone, fundamentalmente, las concepciones del Dios de los filósofos y del de los santos y místicos.

Ahora bien, al designarse lo Numinoso por el ideograma «Mysterium tremendum» no debe entenderse el término «tremendum» como mera explicación de "Mysterium», al ser más bien "un predicado sintético» ${ }^{225}$. Estrictamente se deben separar ambos términos: «A veces predomina el misterio y se manifiesta con tal pujanza que el otro retrocede y casi llega a extinguirse» ${ }^{226}$.

El «Mysterium» por sí solo, separado de lo "tremendum» puede ser designado con mayor exactitud con el término «mirum». "Mirum» que no es aún «admirandum», ya que este momento vendrá condicionado por el "fascinans» y el "augustum». Todavía «mirum» no equivale a "admirar», sino tan solo a asombrarse y sorprenderse: «asombrarse en su verdadero sentido, porque éste, al principio es un estado de ánimo que se manifiesta exclusivamente en la esfera de lo Numinoso y sólo en una forma desvaída, que llamamos asombro, se trasfiere y pasa a otras esferas» ${ }^{227}$.

220. I.c., 13.

221. I.c., 21.

222. Das Heilige, 22.

223. I.c., 23.

224. I.c., 27.

225. I.c., 29.

226. Ibd.

227. I.c., 31 . 
El reflejo sentimental del «asombrarse» responde al ideograma de lo «totalmente-otro».

El aspecto de lo Numinoso, que R. Otto llama "misterio» experimenta, según él, en casi todas las direcciones de la evolución histórica de la Religión, una transformación. En ésta se distinguen tres grados:

a) El de siempre-sorpresa;

b) El de paradoja;

c) El de antinomia.

El primero está formado por lo inaprehensible, incomprensible. El segundo expresa lo que escapa a nuestros conceptos, al trascender todas las categorias de nuestro pensamiento, no sólo las rebasa, sino que, a veces, parece ponerse en contradicción a ellas; entonces se convierte en paradoja. La forma extrema de esto es lo que se llama antinomia.

Desde aquí intenta R. Otto, comprender la mística, que es una profunda teología del «mirum», y de lo "totalmente-otro». En cuanto lo considera, no solamente opuesto, a lo natural y cósmico sino también al ser y al ente, lo designa como «nada». Recordemos la expresión de San Juan de la Cruz: "Y sobre el monte nada, nada, nada». Con este término no sólo se designa lo que no es determinable por nada, sino lo total y cualitativamente otro, opuesto a todo. Al elevarse la negación a la paradoja se proyecta de una manera concreta la cualidad positiva de lo "totalmente-otro" sobre el sentimiento, apareciendo asi la mistica, como una supertensión de los momentos irracionales.

El contenido cualitativo de lo Numinoso, que se presenta bajo la forma de misterio, está constituido por una parte, por el elemento del "Tremendum» que distingue $y$ distancia con su majestad. Al mismo tiempo es algo que atrae y ufascina». Ambos elementos atrayente y retrayente, vienen a formar una extraña armonía de contrastes ${ }^{228}$.

Aún destaca R. Otto un último momento de lo Numinoso: está en conexión con el "sentimiento de creatura», que consiste - como ya hemos vistoen la experiencia de la nada propia. Ahora - insiste R. Otto - que no hay que concebir esto de una manera moral: la desvaloración no tiene, por tanto una dimensión ética, al no tratarse de actos concretos. Es el ser de toda creatura en cuanto tal al que connota esta desestimación. La creatura experimenta en este momento de lo Numinoso la realidad de su ausencia de valor, su carácter profano frente a lo «Santo»: «Esta santidad no es perfección, belleza, ni tampoco bondad. Por otro lado; se manifiesta sensiblemente con estos conceptos, pues como ellos, es un valor y un valor objetivo, y por último un valor infinito que no puede ser nunca sobrepujado. Es el valor numinoso, al que corresponde del lado de la creatura un valor negativo-numinoso" ${ }^{229}$.

Para subrayar el carácter axiológico absoluto de este momento de lo $\mathrm{Nu}$ -

228. Das Heilige, 42.

229. I.c., 67. 
minoso, rechaza R. Otto, la traducción de lo Santo por lo «Supracósmico»: «su defecto principal estriba en que «supracósmico» es una expresión que se refiere meramente al ser y no al valor y por otra parte, porque lo «supracósmico» doblega y humilla por la fuerza, y no por respeto aprobativo» ${ }^{230}$. Para expresar este momento de lo Numinoso escoge R. Otto, el ideograma del "augustum».

El «fascinans» sería el Numen en cuanto tiene un valor subjetivo, y el «augustum» en cuanto posee un valor objetivo que debe ser respetado.

Al ser el «augustum» un elemento esencial del Numen, la Religión es esencialmente y aún prescindiendo de toda esquematización ética «una obligación íntima que se impone a la conciencia y, a la vez, que la conciencia siente; es obediencia y servicio, que son debidos, no por la coacción del poderío, sino por espontánea sumisión al valor santísimo» ${ }^{231}$.

Aunque M. Scheler invoque en De lo Eterno en el hombre la aportación de R. Otto sobre lo "Santo», no hay que interpretar su postura como un completo plegarse a su pensamiento. Lo Santo no constituye para M. Scheler, ninguna "armonía de contraste» ${ }^{232}$, tiene una esencia indivisible, cuyo núcleo más profundo está constituido por el amor: «Si queremos atribuir a Dios la suma cualidad moral en un modo de ser infinito, solamente lo podemos, haciendo del amor, su íntima esencia y diciendo: Dios es un infinito amar. En este núcleo del centro de actos divinos y sólo en él se encuentra su "todo bondad" y su absoluta perfección moral como atributos» ${ }^{233}$. Aquí, está precisamente, la causa de que la persona infinita, que como tal, puede «callarse», se abra al hombre.

Díos aparece en $\mathrm{M}$. Scheler, como «deus absconditus», pero en cercanía constante al hombre ${ }^{234}$. Este hecho contrasta vigorosamente con el juego que nos presenta R. Otto - en dependencia clara de Lutero - en la variabilidad de la cercanía y distancia de lo Numinoso, ya que «ninguna creatura podría soportar ni con frecuencia ni durante largo tiempo la cercanía de la majestad divina, en su momento de dicha y de pavor» ${ }^{235}$.

A esta diferencia en la concepción del núcleo fundamental de lo «Santo» hay que añadir otra proveniente del carácter personal que subraya ante todo, M. Scheler.

La «personalidad» es, en R. Otto, un «esquema» que pertenece a los atributos racionales de lo Divino. En $\mathrm{M}$. Scheler, por el contrario, pertenece a la esencia de lo Santo el ser persona: si la doctrina axiológica general, lleva a un

230. I.c., 68 .

231. I.c., 69 .

232. Das Heilige, 56.

233. Symp., 177.

234. Ew. M. 333.

235. R. Otto, Sünde und Urschuld, 188. 
valor absoluto y supremo la del «valor de las personas» - siempre superior al «valor de las cosas»-, ha de tener como consecuencia la idea de lo Santo como persona infinita.

\section{DETERMINACIONES MATERIALES DE LO DIVINO}

Los atributos "positivos», "materiales», de Dios, presuponen esencialmente, las determinaciones formales por las que lo Divino aparece en su correlato subjetivo, el acto religioso, originariamente como ser absoluto y santo.

Ya insinuamos al comenzar este capítulo, que es distinto el método de constatación de las determinaciones formales y de los atributos materiales, respectivamente. Aquéllas upueden manifestarse en los actos religiosos de cualquier ser, esté constituido como quiera» ${ }^{236}$. En cuanto a los atributos materiales «resulta co-determinante, la articulación esencial de los hechos y valores del mundo, que se manifiestan al hombre en la experiencia total de aquél, y según los que éste concibe todo ser contingente» ${ }^{237}$. Dios es, pues, conocido, aquí, en el «espejo del mundo» ${ }^{238}$. El método que lleva a la constatación de las determinaciones materiales de lo Divino, consiste en pensar «que este mundo sea su posible revelación esencial natural y que su obra sea creatura suya" ${ }^{239}$.

Aunque no ha de interpretarse este proceso metódico como una "conclusión», puede reducirse, sin embargo, el acto religioso donde aparecen estas determinaciones a la forma de un raciocinio, aunque no sea "causal sino analógico" ${ }^{240}$. De aquí que las determinaciones materiales de lo divino, sean en su validez «meramente inadecuadas, inexpresivas y exclusivamente analógicas»" ${ }^{241}$.

Son inadecuadas, al ser la esencia divina infinitamente más rica.

Se presentan como inexpresivas, porque sabemos que "con expresiones como espíritu, razón, voluntad, etc., de Dios, no afirmamos en él partes de ninguna especie, ni reales ni abstractas, sino que sólo subrayamos semejanzas esencial y gradualmente escalonadas poseídas por un ser completamente simple e indivisible, de esencia específicamente distinta a la del ser divisible y finito» 242 .

Finalmente aparece la dimensión analógica de las determinaciones mate-

236. Ew. M. 169.

237. Ew. M. 171-172.

238. Ew. M. 176, nota 1.

239. Ew. M. 172.

240. Ibd.

241. Ibd.

242. Ew. M. 173. 
riales de lo divino en que éste aparece siempre como «áppri६४v», como inefable, trascendiendo todas las categorías de nuestro pensamiento.

Aclarados estos presupuestos generales pasamos a su estudio concreto.

Dentro de los «atributos positivo-naturales» de lo divino subraya $M$. Scheler la «espiritualidad» como la determinación material «más fundamental» al resumir, en cierto sentido, a todas las demás ${ }^{243}$.

Ahora bien, cuando en El formalismo en la ética y la ética material de los valores y en De lo Eterno en el hombre habla M. Scheler de "espíritu», habla del «ser-personal»: "La persona es, con necesidad esencial, la única forma de existencia del espíritu, en cuanto se trata de un espíritu concreto" ${ }^{244}$.

Según esto, pueden reducirse, fundamentalmente, a dos las determinaciones materiales que, dentro de la óntica esencial de lo divino, destaca $M$. Scheler: espíritu y persona, pero sólo en cuanto ésta está vinculada a aquél.

En la exposición del tema del hombre en la fenomenología de M. Scheler analizaremos detenidamente estos dos conceptos, vertebrales sin duda, en el pensamiento scheleriano y también en el objetivo de nuestro trabajo.

Para no incidir en repeticiones, remitimos a los capítulos respectivos, de nuestra-Tercera Parte, ya que el constitutivo «espiritual» de lo divino igual que el «personal» implicado en él -en cuanto determinación material «brota de la consideración de aquella parte del mundo que es el hombre» ${ }^{245}$.

Nuestra intención, por el momento, se cifra, pues, en reseñar, someramente, el sentido de las determinaciones materiales de la óntica esencial de lo divino en $\mathrm{M}$. Scheler, en la conciencia de que una comprensión adecuada de las mismas sólo puede lograrse por medio del estudio del hombre en cuanto ser «espiritual» y «personal» al que va dirigida nuestra Tercera Parte.

\section{Lo divino como espiritu}

Como hemos visto ya «el atributo positivo-analógico de lo divino más fundamental es el de la espiritualidad $\gg{ }^{246}$. Esta determinación material brota de la consideración del mundo $y$, de una manera particular, de aquella parte del mundo que es el hombre. Al experimentarse éste como ser espiritual se encuentra con lo divino en cuanto espíritu. De aquí que $M$. Scheler afirme: "Un alma bastaría para conocer a Dios como espíritu. Sin embargo, no bastaría el mundo" ${ }^{247}$.

Ahora bien, si el hombre solamente desde la atalaya de su experiencia es-

243. Ew. M. 178.

244. Eth. 389.

245. Ew. M. 193.

246. Ew. M. 178.

247. Ew. M. 193. 
piritual puede llegar a lo divino como espíritu ¿Cómo puede entenderse que este ser espiritual sea origen de todo ser?

M. Scheler lo explica por la relación entre el espíritu humano y el mundo, por la dependencia esencial que tiene el mundo, en un sentido integral, con respecto a un espíritu por antonomasia, y últimamente por la inmanencia del mundo en tal espíritu.

A este espíritu divino hay que atribuirle «los atributos formales de la absolutividad e infinitud» ${ }^{248}$. Por el primero se funda el espíritu divino en sí mismo de manera exclusiva y de aquí emerge la libertad omnímoda y la autodeterminación absoluta.

El «Ens a se», aparece ahora como «ens per se» y "sólo así puede entenderse el modo de su obrar como análogo al querer y su causalidad como la causalidad de tipos espirituales de la libertad y potencia creadora» ${ }^{249}$.

El proceso y desarrollo de la acción humana, sirve aquí de punto de partida para el conocimiento de Dios-creador.

Ahora bien, el acto creador no sólo tiene una dimensión intelectiva, sino también volitiva que hace que la idea tome forma y que la materia sea informada por su principio determinante.

Con la determinación esencial de lo Divino como espíritu creador, aparece Dios como espíritu infinito, que es Uno frente a lo múltiple, Eterno frente al tiempo, Super-espacial con relación al espacio, llimitado frente a lo finito $y$ Omnipresente en todo.

Hemos visto que lo Divino es espíritu, pero «no omnipotencia ciega» ${ }^{250}$; ha de darse en él todo lo que incluye el espíritu humano en un grado eminente, «por eso, la intuición pertenece al Logos de Dios, como el llamado pensamiento racional» ${ }^{251}$ y por eso también se da en el espíritu divino no sólo entendimiento intuitivo, sino también voluntad. Esta determinación material surge al contacto con la contingencia del cosmos: «sólo por esto tenemos ahora también el derecho de concluir que la causa del ser real del mundo es $\left.1 .^{\circ}\right)$ única y suprema (se sigue del ens a se, como causa); $2 .^{\circ}$ ) voluntaria: el querer es el único caso, que se nos da de una función espiritual, por la cual pasamos un «algo» determinado simplemente en idea al plano de ser real, lo vemos convertirse en ser real») ${ }^{252}$.

Así como el espíritu divino no puede ser solamente entendimiento intuitivo, tampoco es exclusivamente voluntad: «Un Dios que sólo fuera voluntad eterna, sólo desde sí necesaria, y ninguna otra cosa, como amor, logos o también que fuera tal voluntad primariamente, no se distinguiría de un poder fatal universal» 253 .

248. Ew. M. 186-187.

249. Ew. M. 186-187.

250. Ew. M. 178.

251. I.c., 212.

252. I.c., 214.

253. I.c., 219. 
El entendimiento y la voluntad se fundan en el amor. En la esfera de lo Divino está el amor también sobre aquéllos y es la base de su unidad: «En el principio no era la acción, sino el logos guiado por el amor» ${ }^{254}$. La Creación se explica, fundamentalmente, por este amor de Dios. De ahí que estime M. Scheler que los griegos no hayan podido conocer este hecho ${ }^{255}$. Tanto Platón como Aristóteles, ignoran el amor en lo Divino, al concebirle exclusivamente desde una vertiente de indigencia, siendo, pues, contrario a lo que es en sí esencialmente suficiente.

\section{UNA SUTIL DISTINCIÓN SCHELERIANA.}

Recordemos nuevamente que las «determinaciones materiales» de lo divino se logran, en expresión de $M$. Scheler, en virtud de un raciocinio «no causal sino analógico» ${ }^{256}$; recordemos que «Dios es conocido aquí (en las determinaciones materiales) en el espejo del mundo») ${ }^{257}$.

Hay que proceder con cautela, al estimar que el terreno que vamos a pisar es tan original y sutil como controvertible.

El constitutivo «personal» de lo divino sólo puede pertenecer a la categoría de «determinación material» en cuanto podemos trepar hasta él partiendo del mundo, concretamente del hombre.

Si el hombre es espíritu, lo divino al poseer en grado eminente toda perfección que en último término tiene su fundamento en él, ha de ser también espíritu.

Si el espíritu es esencialmente personal, ya que la «persona es, con necesidad esencial, la única forma de existencia del espíritu, en cuanto se trata de un espíritu concreto"» ${ }^{258}$, al ser lo divino espíritu ha de ser también persona.

$\mathrm{Si}$ los valores de las personas son superiores a los valores de las cosas ${ }^{259}$, ha de implicar este principio axiológico que la idea del «Summun Bonum» tiene que encerrar en si el carácter personal.

Más aún, si a toda persona corresponde un mundo $y$ a todo mundo una persona y ambos - persona y mundo - constituyen un macrocosmos ${ }^{260}$; si cada mundo de las personas exige un miembro de relación personal, el mundo como facticidad que se refleja en las personas singulares exige una unidad suprema, una persona absoluta: Dios. Lo divino aparece así como persona.

Podríamos decir que únicamente puede llegar hasta aquí la «determinación materialı de lo divino como persona.

254. I.c., 220.

255. Ew. M., 220.

256. Ew. M. 172.

257. Ew. M. 173. nota.

258. Eth. 389.

259. Eth. 117.

260. Eth. 395ss 
Sin embargo, con esto no habríamos logrado gran cosa. Hablando con exactitud no habríamos logrado nada respecto a la persona de Dios.

M. Scheler nos da la clave para comprender esta aparente contradición.

Él está en principio de acuerdo en que «con la ayuda de los principios de la ética y de la metafísica - mejor metapsicología - es cognoscible de una manera mediata la espiritualidad del alma humana», está de acuerdo en que «el Ens a se ha de ser personal según su ser-así» ${ }^{261}$, sin embargo, a renglón seguido, añade:

«Debo señalar en primer lugar que existe una importante diferencia entre el conocer a Dios como persona y entre conocer a una persona que se manifiesta como Dios.

El conocimiento mediato de Dios como persona se refiere a lo primero y la tesis de la prueba de la indemostrabilidad de Dios como persona hace referencia al segundo" ${ }^{262}$.

Toda inferencia metafísica o metapsicológica, toda conclusión axiológica llega al ens a se que debe ser espíritu que debe ser persona, pero no llega directamente a su ser personal. El ser personal de lo divino ha de «aparecer» en el acto de la experiencia religiosa inmediata, correlato esencia de la revelación de la persona de Dios.

Para comprender la sutil distinción scheleriana entre Dios como persona y persona como Dios podríamos apoyarnos en el siguiente ejemplo:

El azul que vemos es precisamente el azul que llena nuestra vista (experiencia) y no sólo «un» color con una longitud de onda $X$, que no ha inundado nunca nuestros ojos (concepto).

Conocemos el azul cuando se nos da en una intuición de azul y no en un espectro físico.

En un sentido similar afirma M. Scheler que podemos tener un conocimiento (formal) de Dios como persona, pero con esto no conocemos nada de la personalidad de Dios ya que tal conocimiento se nos da sólo cuando tenemos un conocimiento (material) de "una persona en cuanto Dios».

Podríamos aclarar también la sutil distinción cheleriana anticipando un aspecto de su análisis sobre la persona:

Como veremos en la Tercera Parte, la persona - según el criterio de $M$. Scheler - se da solamente en la coejecución de sus actos. Si aplicamos esto a la persona absoluta de Dios, constatamos que la metafísica llega a la upersonalitas» "viae formae». Pero para que nos «encontremos» con la persona verdadera y concreta de Dios es necesario que el espíritu humano co-realice los actos de la persona de Dios, en el acto de la experiencia religiosa, de una manera especial, el acto del amor, en el que están comprendidos, en cierto sentido, todos: «Si se piensa a Dios como persona, el saber de esta persona no es

261. Ew. M. 20.

262. Ibd. 
tampoco concebible como saber de algo objetivo, sino sólo como "cogitare», "velle», "amare», «in Deo», e.d., como co-ejecución de la misma vida divina y como un oír su palabra por medio de la cual nos atestigua él mismo... su existencia como persona» ${ }^{263}$. M. Scheler al moverse en el horizonte de la "experiencia religiosa» rechaza todo criterio que "garantice» la realidad de la persona divina.

Ya hemos dicho - y lo veremos en el próximo capítulo - que el acto religioso tiene como correlato noemático la revelación, la auto-manifestación de él, siendo una reacción a la acción divina, una respuesta a la palabra de Dios en la que se manifiesta como persona.

La estructura interna del pensamiento de $M$. Scheler a este respecto podría reducirse, según lo que hemos expuesto, a estos tres puntos:

a) No es posible ningún conocimiento de la personalidad de Dios partiendo de la metafísica del mundo infrahumano, ya que no está realizada aqui en absoluto la idea de la "personalitas», prohibiendo la doctrina de las «esferas del ser» todo tránsito de una a otra, al ser irreductibles entre sí: Del color no se puede llegar al sonido.

b) La metafísica general (incluida la metapsicología y la ética) sólo puede proporcionarnos un conocimiento de Dios igual a cero. Es posible, sin duda, un conocimiento de Dios como persona, pero éste es totalmente nulo con respecto a la persona de Dios. Ya hemos tratado con anterioridad esta infravaloración de la metafísica por parte de M. Scheler.

c) El conocimiento auténtico de la personalidad de Dios solamente es posible por medio de la automanifestación de Dios: «No es pues un defecto de 'nuestro' poder cognoscitivo, ni un límite de este poder, es una consecuencia esencial del mismo objeto... que el qué de la personalidad de Dios no pueda dársenos en virtud de actos de conocimiento espontáneo sino por un acto libre de auto-manifestación de la persona divina» ${ }^{264}$.

Aquí, precisamente, radica para $M$. Scheler su «intuición de la indemostrabilidad de Dios como persona") ${ }^{265}$.

La persona y el espíritu representan un modo de ser que es por esencia trasinteligible a todo conocer espontáneo len el contraste más radical con lo inorgánico y orgánico) puesto que «entra en su libre albedrío... el darse a conocer o no" ${ }^{266}$.

Ahora bien, no sólo pertenece a Dios el «ser-personal», sino también el amor como supremo valor de actos.

Desde esta perspectiva de amor infinito, Dios, con necesidad esencial, no puede «callar». Esta necesidad no indica ninguna clase de coacción, sino que es la expresión de la libertad más originaria hecha amor.

\section{H. MARTIN IZQUIERDO}

263. Sym. 241, nota.

264. Ew. M. 331.

265. Ibd.

266. Sym. 242. 